Max-Planck-Institut für demografische Forschung

Max Planck Institute for Demographic Research

Konrad-Zuse-Strasse 1 - D-18057 Rostock - GERMANY

Tel +49 (0) 3812081 - 0; Fax +49 (0) 3812081 - 202;

http://www.demogr.mpg.de

MPIDR WORKING PAPER WP 2016-011

OCTOBER 2016

\title{
Parental Age and Offspring Mortality: \\ Negative Effects of Reproductive Aging are Outweighed by Secular Increases in Longevity
}

Kieron Barclay (barclay@demogr.mpg.de)

Mikko Myrskylä (sekmyrskyla@demogr.mpg.de)

(C) Copyright is held by the authors.

Working papers of the Max Planck Institute for Demographic Research receive only limited review. Views or opinions expressed in working papers are attributable to the authors and do not necessarily reflect those of the Institute. 


\title{
Parental Age and Offspring Mortality: Negative Effects of Reproductive Aging are Outweighed by Secular Increases in Longevity
}

\author{
Kieron Barclay,2,3 and Mikko Myrskylä1,2,4 \\ ${ }^{1}$ Department of Social Policy, London School of Economics and Political Science \\ ${ }^{2}$ Max Planck Institute for Demographic Research \\ 3Department of Sociology, Stockholm University \\ ${ }^{4}$ Population Research Unit, Department of Social Research, University of Helsinki
}

\begin{abstract}
As parental ages at birth continue to rise, concerns about the effects of fertility postponement on offspring are increasing as well. Advanced maternal and paternal ages have been associated with a range of negative health outcomes for offspring, including decreased longevity. The literature, however, has neglected to examine the benefits of being born at a later date. We analyse mortality among 1.9 million Swedish men and women born in 1938-1960, and use a sibling comparison design that accounts for all time invariant factors shared by the siblings. We show that there are no adverse effects of childbearing at advanced maternal ages, and that offspring mortality declines monotonically with advancing paternal age. This positive effect is attributable to the increase in life expectancy over successive birth cohorts, which dominates over individual-level factors that may have negative effects on offspring longevity, such as reproductive ageing.
\end{abstract}




\section{Introduction}

In recent decades, the postponement of parenthood has been one of the most prominent demographic trends across developed countries (UN, 2014). In the United States, the mean maternal age at first birth increased from 22 in 1970 to 26 in 2010, while in Sweden the mean age at first birth has reached 30 (Human Fertility Database). The trends are similar for paternal age. As Figure 1 shows, a mean age at childbearing approaching age 30 is not historically unusual in Sweden or many other contemporary developed countries. Indeed, the mean age at childbearing was near, or above, age 30 in Canada, Japan, and Sweden earlier in the 20th century. However, given the relationship between parental age at childbearing and offspring health, the recent increase in the mean age at childbearing could have important consequences for population health. Previous research suggests that the offspring of older parents have higher mortality and lower reproductive fitness (Kemkes-Grottenthaler, 2004; Smith et al., 2009; Gavrilov and Gavrilova, 2012; Gillespie et al., 2013). Advanced maternal and paternal ages at birth are also associated with a range of negative pregnancy and peri-natal outcomes, including an increased risk of spontaneous abortion, Down syndrome, and childhood cancer (Andersen et al., 2000; Yip et al., 2006), as well as Alzheimers disease and schizophrenia in adulthood (Rocca et al., 1991; Sipos et al., 2004). These negative consequences of advanced parental age are primarily concentrated amongst offspring born to parents who are 35 or older.

*** Figure 1 Approximately Here ${ }^{* * *}$

In considering the impact of parental age at childbearing on offspring health and 
longevity, there are at least three important dimensions to consider. The first is the physiological effect of parental age on offspring health, which is attributable to reproductive ageing (Hassold and Hunt, 2001; Tatone et al., 2008; Kong et al., 2012). The second is the importance of parental socioeconomic status. Older age at childbearing is consistently associated with higher levels of income, occupational attainment, and earnings (Powell et al., 2006), and given the strong relationship between socioeconomic status and health (Mackenbach et al., 1997; Torssander and Erikson, 2010), children born to older parents are likely to be at an advantage. A third factor is the importance of macro-level trends for influencing offspring outcomes, which until recently has been completely ignored by research on this topic (Myrskylä et al., 2013; Barclay and Myrskylä, 2016). For any prospective parent, delaying parenthood means that his or her child will be born at a later date. Maximum human life expectancy has increased at a rate of more than two years per decade for over a century (Oeppen and Vaupel, 2002), and Sweden has experienced a similar pattern of improvement (see Figure 1). Life expectancy at birth in Sweden in 1900 was 53.6 for women, and 50.8 for men, but by 2014 it was 84.1 for women, and 80.4 for men.

In the early 1970s Sweden was the world leader in life expectancy at birth, but it has since lost ground to countries like France and Japan (Drefahl et al., 2014). Akin to the pattern in other developed countries, gains in period life expectancy at birth earlier in the 20th century were primarily attributable to declines in infant and child mortality, while improvements since the 1950s are primarily attributable to declines at older ages (Christensen et al., 2009). Although mortality decline amongst centenarians has stagnated (Drefahl et al., 2012), there have still been very substantial reductions in the rates of mortality attributable to cancers and diseases of the circulatory system amongst 
pre-centenarians (Björck et al., 2009; La Vecchia et al., 2009; Modig et al., 2013). Given that cancer and cardiovascular disease are also the two leading causes of death in Sweden, this study will examine the relationship between parental age and mortality attributable to these causes in addition to all-cause mortality.

In this study we use Swedish population data to study the relationship between parental age at the time of birth and offspring mortality in adulthood over the period 1990 to 2012. Figure 2 shows age-adjusted mortality trends over the period 1990 to 2012 for mortality attributable to all causes, mortality attributable to tumours, mortality attributable to cardiovascular diseases, and mortality attributable to external causes. Men are shown in the left-panel, and women in the right-panel. The declines in all-cause mortality were large for both men and women in this period. In 1990 the all-cause mortality rate for men was 1,543 per 100,000 for men and 989 per 100,000 for women, and this declined to 1,071 per 100,000 in 2012 for men, and 782 per 100,000 for women (Socialstyrelsen, 2007, 2013). Declines in mortality attributable to cardiovascular diseases, or diseases of the circulatory system, were also substantial for both men and women, but particularly so for men. For men mortality attributable to cardiovascular diseases declined from 801 to 412 per 100,000 between 1990 and 2012, and for women mortality attributable to cardiovascular diseases declined from 508 to 286 per 100,000 between 1990 and 2012 (Socialstyrelsen, 2007, 2013). Although it is more difficult to discern in Figure 2, there were also meaningful declines in mortality attributable to cancers between 1990 and 2012. For men mortality attributable to cancers declined from 322 per 100,000 in 1990 to 279 per 100,000 in 2012, while for women mortality attributable to cancers declined from 215 per 100,000 to 200 per 100,000 in 2013 (Socialstyrelsen, 2007, 2013) 
*** Figure 2 Approximately Here ${ }^{* * *}$

Postponing parenthood, or continuing childbearing at older ages, means placing that child into a later birth cohort. As a result of the declines in age-specific mortality in Sweden, clearly demonstrated in Figures 1 and 2, the members of these later born cohorts are likely to live longer than if they had been born into an earlier time period. In this study we investigate whether secular trends of increasing longevity may counterbalance or even outweigh the negative effects of reproductive ageing on offspring longevity for any individual mother or father. In this study we use Swedish population data to study adult mortality, between ages 30 and 74, to examine the longterm impact of parental age at the time of birth on offspring health.

Parental Age and Offspring Longevity: Counterbalancing Processes.

While the risks associated with reproductive ageing are well-established, older parents typically have access to greater economic and social resources, which may offset some of the physiological ageing effects (Powell et al., 2006). Older mothers typically have greater levels of education (Lappegård, 2000), higher incomes, higher occupational status (McLanahan, 2004), and due to assortative mating are partnered with men who also have high socioeconomic status (McPherson et al., 2001; Mare, 2016). Studies also show that older parents are more likely to be in stable relationships (Thomson et al., 2014), and relative to younger couples they are happier after they have children (Margolis and Myrskylä, 2011; Myrskylä and Margolis, 2014). Childbearing in the teenage years or in early adulthood is most common amongst men and women from less 
advantaged socioeconomic backgrounds (Hoffman et al., 1993), and even when this is not the case, childbearing at relatively early ages disrupts educational and occupational trajectories, leading to lower socioeconomic attainment and health (Klepinger et al., 1995; Barclay et al., 2016). As a consequence, the children of older parents are generally the beneficiaries of greater resources, and higher parenting quality (Kalil et al., 2012). This disparity in the resources available to children of high socioeconomic and low socioeconomic status parents has been growing since at least the 1970s (McLanahan, 2004).

However, despite the potentially beneficial impact on children of having access to additional social resources, most evidence still suggests that advancing parental age is associated with decreased offspring longevity (Kemkes-Grottenthaler, 2004; Smith et al., 2009; Gavrilov and Gavrilova, 2012). Reproductive ageing is thought to be the primary explanation for why the children of older parents have worse birth outcomes, and worse long-term health. Human reproductive systems deteriorate with increasing age, and increasing maternal age is associated with the accumulation of DNA damage in the germ cells and decreasing embryo viability, leading to lower fecundity (Abdalla et al., 1997). Studies show that the likelihood of spontaneous abortion, still birth, Down syndrome, as well as the risk of poor peri-natal outcomes such as pre-term birth and low birth weight, increase exponentially from around age 25 for potential mothers (Cnattingius et al., 1992; Andersen et al., 2000). Increasing paternal age is an important determinant of de novo mutations in the male germ cells (Kong et al., 2012), and later paternal age has been found to be associated with an increased risk of schizophrenia and autism (Sipos et al., 2004; Hultman et al., 2011). 
While the evidence for the relationship between parental age and offspring mortality is relatively clear, studies on this topic have invariably ignored the role of macro-level trends in determining offspring outcomes. As shown in Figure 1, life expectancy at birth in Sweden and many other developed countries has been increasing consistently across the 20th century, excepting short-term dips attributable to major international conflicts. For any individual mother or father, postponing childbearing, or continuing childbearing, at older ages invariably means giving birth into a later birth year. Due to the improvements in medical knowledge and public health conditions in the intervening period in which older parents have delayed childbearing, their children are likely to benefit from these improvements in social conditions. For example, in 1940 in Sweden life expectancy at birth was 67, but in 1960 life expectancy at birth had increased to 73 . Ceteris paribus, a child born into this later birth year would be expected to live longer. In this study we evaluate the extent to which these secular improvements in longevity counterbalance or even outweigh the negative effects of reproductive ageing net of the socioeconomic status of the parents.

\section{Data and Methods}

Data

In this study, we use Swedish administrative register data to examine individuals born in Sweden between 1938 and 1960, inclusive. In Sweden, each individual has a unique personal identification number (PIN). This PIN makes it possible to link the records of an individual across the various administrative registers. One particularly important 
register for this study is the Swedish multi-generational register. The multi-generational register contains information on the PIN of each individual, as well as the PINs of the individual's parents (Statistics Sweden, 2011). This information allows us to identify the biological mother and father of each individual, and, in turn, to identify any other biological kin relations. The main family members of interest in this study are the mother, father, and siblings of the index persons. We use information on the biological mother and father to determine the maternal and paternal ages at the time of birth, and to identify the sibling group. The earliest birth cohort for which it is possible to link individuals to their siblings in the Swedish multi-generational register is 1932 . However, we use cohorts born from 1938 to 1960 as previous studies have suggested that birth order may influence long-term health and mortality (Barclay and Myrskylä, 2014; Barclay and Kolk, 2015). Since we can only link individuals to their kin from 1932, everybody born in 1932 appears in the data as a 'first born'. To be able to have a more accurate measure for birth order, we start from cohorts born in 1938.

Although we describe our methodological strategy in more detail in the following section, our strategy is also related to the analytical sample that we use. Between 1938 and 1960 there were 2,491,059 births in Sweden. After excluding individuals who are missing information on the ID of the mother or father, sibling groups where any child is born outside of Sweden, and sibling groups with multiple births, we were left with 1,899,314 observations. In our main analyses we employ within-family sibling comparison analyses, comparing siblings who share a biological mother and father. These sibling comparison analyses rely on variance in the sibling group to estimate the importance of parental age at the time of birth. That means that our sibling fixed effect analyses are based on sibling groups where at least two siblings are observed, and 
where at least one sibling has died. This results in an analytical sample of 319,749, experiencing 117,169 deaths. Although within-family sibling comparisons have a high degree of internal validity, there are limitations to generalisability when such a large proportion of the population is excluded from the analyses. To address this, we also use between-family comparisons that do not exclude one-child sibling groups or sibling groups where none of the siblings have died. The analytical sample for those analyses is 1,899,314 experiencing 157,328 deaths. We provide more detail on our statistical models in the following section.

To study mortality we use the Swedish death register, which covers the period 19602012. Although the Swedish mortality register contains data over the period 1960 to 2012, the multigenerational registers that allow family members to be linked to one another are incomplete before the 1990s (SCB, 2011). As a consequence, studying mortality prior to the early 1990s for individuals who can be linked to their kin is, in effect, still conditioning on survival to the early 1990s for members of that population. This is particularly important as a central component of our analysis is the application of a within-family sibling comparison approach, detailed below in the following section. We have therefore chosen to study mortality over the period January 1990 to December 2012. Although we could also study cohorts born later than 1960, we choose to focus on these cohorts born 1938-1960 to somewhat limit the degree of cohort and period heterogeneity in mortality patterns. Furthermore, mortality in early adulthood in Sweden is uncommon, meaning that few deaths are observed amongst cohorts born later than 1960 before 2012, the latest point for which we have data on mortality. 
To study mortality, we use survival analysis in the form of Cox proportional hazard regressions (Cox, 1972). The proportional hazards model is expressed as:

$$
h\left(t \mid X_{1}, \ldots, X_{k}\right)=h_{0}(t) \exp \left(\sum_{j=1}^{k} \beta_{j} X_{j}(t)\right)
$$

where $h\left(t / X_{1} \ldots X_{k}\right)$ is the hazard rate for individuals with characteristics $X_{1} \ldots X_{k}$ at time $t, h_{0}(t)$ is the baseline hazard at time $t$, and $\beta_{j}, j=1, \ldots, k$ are the estimated coefficients. Since the failure event in our analysis is the death of the individual, the baseline hazard of our model, $h_{0}(t)$, is age. Since we study mortality between 1990 and 2012, the age from which we begin to follow-up individuals in our analysis is the age of the index person in 1990. For individuals born in 1938 that is 52, whereas for individuals born in 1960 that is age 30. We observe individuals born in 1938 between ages 52 and 74, and individuals born in 1960 between ages 30 and 62. Individuals are censored on first migration out of Sweden, at death, or in 2012; whichever comes first.

To estimate the relationship between parental age and offspring mortality we use four different models. Models 1 and 2 use the full cohorts of individuals born 1938-1960 and use between-family analyses to examine the relationship between parental age at time of birth and offspring mortality. Models 3 and 4 use within-family comparisons analyses on the subset of sibling groups with more than one child that have experienced at least one death amongst the siblings.

Model 1 is a descriptive model that examines the associations between maternal and paternal ages and mortality using a standard Cox model, and interacts offspring sex with 
maternal and paternal age at the time of birth. Model 2 is a between-family comparison design where we use the full cohort of men and women born in Sweden between 1938 and 1960 to examine how parental age at the time of birth is related to offspring mortality. In a variant of Model 2, we interact parental birth cohort with parental age at the time of birth to examine how delaying childbearing to older ages, or continuing childbearing at older ages, is related to offspring mortality for parents born in different cohorts. In these analyses we examine the mortality of children born to parents of three different cohorts, which are those born 1885-1919, 1920-1929, and 1930-1946.

In Model 2 we control for offspring sex, offspring birth order, sibling group size, the length of the birth interval preceding the birth of the index person, the highest level of education achieved by the mother, the highest level of education achieved by the father, and we also include time-varying covariates for the death and migration status of the mother and father. As mentioned above, previous research has shown a relationship between birth order and health (Barclay and Myrskylä, 2014; Barclay and Kolk, 2015), and other studies show a relationship between sibling group size and health (Hart and Davey-Smith, 2003), both of which are associated with parental age at childbearing. The length of the preceding birth interval is also associated with peri-natal outcomes (Conde-Agudelo et al., 2006), which are in turn associated with long-term mortality (Osler et al., 2003). Parental education is also strongly associated with offspring health (Hayward and Gorman, 2004), and more highly educated parents tend to have children at later ages (McLanahan, 2004). We control for the death and migration status of the mother and father as previous research has suggested that there is a relationship between lifespan overlap and offspring longevity (Myrskylä and Fenelon, 2012), and this might explain the relationship between parental age at the time of birth and offspring 
longevity (Myrskylä et al., 2014). The four categories for these death-migration variables are: (1) alive and in Sweden, (2) outmigrated and no mortality observed, (3) dead, and (4) a small number of cases where we have data on death following outmigration. The length of the preceding birth interval is set to zero for first born siblings.

Model 3 estimates the association between parental age and offspring longevity using a within-family sibling comparison, and adjusts for birth order. The sibling comparison reduces residual confounding attributable to time invariant factors shared by the siblings. By excluding a control for birth year Model 3 captures the fact that, for an individual mother or father, delaying childbearing to later ages also means giving birth into a later birth year. Model 3 is intended to investigate what we describe as the 'total effect' of parental age on offspring longevity, which is a combination of parental age at the time of birth, and the year of birth. The results of this model most realistically answer the question of how postponing parenthood affects offspring longevity from the perspective of any individual parent.

Model 4 estimates the association between parental age and offspring longevity using a within-family sibling comparison, and adjusts for birth order, and birth year using oneyear dummies. By including a control for birth year, we estimate what we call the 'partial effect' of parental age at the time of birth. However, although we feel that it is valuable to present the results of Model 4, we urge caution in the interpretation of the estimates. The Cox models that we employ for our statistical analyses use age as the baseline hazard. Furthermore, Model 4 includes covariates for parental age at the time of birth and birth year of the index person. Within a sibling group, a one-year increase in maternal or paternal age is exactly the same as a one-year increase in birth year. The 
dependency of age, period, and cohort mean that it is not strictly possible for us to distinguish the partial effect of parental age at the time of birth within a sibling group from the partial effect of birth year.

We estimate the sibling fixed effects Models 3 and 4 using a stratification design in which siblings share the baseline hazard (Allison, 2009). We also conduct additional analyses to examine effect heterogeneity by cause-of-death. The specific causes that we examine are mortality attributable to diseases of the circulatory system, neoplasms, and all remaining other causes. We take account of the fact that Sweden switched from version 9 to version 10 of the International Classification of Diseases (ICD) in 1996 (Janssen and Kunst, 2004). The diagnostic categories for diseases of the circulatory system in ICD-9 were 390-459, and I00-I99 in ICD-10. The diagnostic categories for neoplasms in ICD-9 were 140-239, and C00-D48 in ICD-10.

\section{Results}

\section{Descriptives}

Table 1 shows summary statistics for the analytical population used in our analyses, based upon the analyses of the full cohorts born 1938-1960, as well as the sibling population with variance on all-cause mortality. It can be seen that in the full population the rate of mortality is lowest amongst those who were born to mothers aged 25-29, and the rate is higher amongst those born to younger and older mothers. In regards to paternal age it can be seen that the rates of mortality are lowest amongst those born to 
fathers aged 20-39. Slightly higher rates of mortality are found amongst those born to teenage fathers, and to fathers aged 40 or older. In the sibling population the pattern is quite different, with those born to older mothers and fathers having lower rates of mortality. However, this is a consequence of conditioning the selection of the sibling population upon the death of at least one of the siblings. Those deaths will be concentrated amongst older siblings, who will be born in earlier cohorts, and will on average will be born to younger mothers and fathers. The descriptive patterns amongst the other variables in Table 1 show that mortality is substantially lower amongst women than men in both the full population as well as the sibling population with variance on all-cause mortality. Rates of mortality are higher following the death of either the mother or father. Since these numbers are descriptive, the death of the mother or father is also correlated with the age of the index person. Finally, it is also clear that rates of mortality are substantially lower amongst those born in later birth cohorts.

\footnotetext{
*** Table 1 Approximately Here ${ }^{* * *}$
}

Survival Analyses: Between-family Analyses Using Full Cohorts.

Tables 2 and 3 show the results from Models 1 and 2, which are between-family analyses examining the relationship between parental age at the time of birth and allcause mortality, mortality attributable to neoplasms, mortality attributable to cardiovascular diseases, and mortality attributable to all remaining causes. Model 1 examines the relationship between parental age and offspring mortality, adjusting only for gender, while Model 2 introduces additional control variables for birth order, sibling 
group size, the length of the preceding birth interval, maternal and paternal educational levels, and the death and migration status of the mother and father. As can be seen from Model 1 in Table 2, individuals born to a mothers and fathers aged 25- 29 have lower mortality than individuals born to younger and older mothers and fathers when looking at all-cause mortality. Those born to teenage mothers and fathers have a hazard $13 \%$ higher, while those born to mothers aged 45 or older, or fathers aged 55 or older have a hazard that is $7 \%$ higher. The results from Model 2 in Table 2 for all-cause mortality show that after adjusting for various confounding factors, those born to teenage mothers and teenage fathers have the highest mortality, and that the hazard of mortality generally decreases monotonically with increasing maternal and paternal age. Figure 3 shows the results for all-cause mortality interacted with the birth cohort of the parents, which we group as 1885-1919, 1920-1929, and 1930-1946. In Figure 3 it is clear that delaying childbearing to older ages has resulted in lower mortality amongst the offspring for both mothers and fathers.

\section{*** Table 2 Approximately Here ${ }^{* * *}$}

\section{*** Figure 3 Approximately Here ${ }^{* * *}$}

Table 2 also shows the results from Models 1 and 2 examining the relationship between parental age at the time of birth and mortality attributable to neoplasms. Model 1 shows that an increased hazard of mortality is only notably associated with being born to a teenage mother or father, and that there is no clear disadvantage in regards to being born to an older mother or father. In Model 2, however, the introduction of the additional control variables shows that increasing maternal and paternal age at the time 
of birth is actually associated with lower mortality for the children. Figure 4(a) show the interaction between the birth cohort of the parents and parental age at the time of birth. As could be seen in Figure 3, increasing maternal and paternal age at the time of birth is associated with lower mortality amongst the offspring. Figure 4(a) shows that there is a small increase in the hazard of mortality for children born to fathers aged 30-34, but this estimate is accompanied by wide confidence intervals.

\footnotetext{
*** Table 3 Approximately Here ***

*** Figure 4 Approximately Here ***
}

Table 3 shows the results from Models 1 and 2 for mortality attributable to cardiovascular diseases and for mortality attributable to all other causes. Model 1 examining mortality attributable to cardiovascular diseases shows that those born to teenage mothers have mortality that is $19 \%$ higher than those born to mothers aged 25 29, while those born to older mothers do not suffer from any clear disadvantage. However, in regards to paternal age, being born to a younger or an older father is disadvantageous. Those born to teenage fathers have a hazard of mortality attributable to cardiovascular diseases that is $23 \%$ higher than those born to fathers aged $25-29$, while those born to fathers aged 55 or older have a hazard of mortality that is $15 \%$ higher. In Model 2, however, it can again be seen that increasing maternal age is associated with lower mortality. Model 2 also shows that being born to an older father is associated with lower mortality up to age 35-39, at which point the decline in mortality levels off. The results from models interacting parental age at the time of birth with parental birth cohort are shown in Figure 4(b). Those models show that the main effects 
of declining mortality with increasing parental age are consistent amongst children born to parents of the three birth cohorts that we examine.

The results from Models 1 and 2 for mortality attributable to all other causes are also shown in Table 3. These results show that being born to both a younger or an older mother is associated with increased mortality, while the same is true for being born to a younger or an older father. The results from Model 2, however, again show that being born to an older mother or father is associated with lower mortality.

Survival Analyses: Within-family Sibling Comparisons

While the estimates from Model 2 are adjusted for a number of potentially confounding variables, it is very possible that there are unobserved factors that vary within the sibling group that might confound the relationship between parental age at the time of birth and offspring mortality in adulthood. To attempt to minimise this residual confounding we estimate sibling comparison models, which adjust for all time-invariant factors that are shared by siblings. Table 4 shows the results from Models 3 and 4 for allcause mortality and mortality attributable to neoplasms, while Table 5 shows the results from Models 3 and 4 for mortality attributable to cardiovascular diseases and all other remaining causes. These results are also shown in Figures 5(a) and 5(b). Note that a hollow datapoint indicates a lack of statistical significance, and a filled datapoint indicates that the point estimate is statistically significant. Model 3 adjust for birth order, giving what we describe as the total effect of parental age at the time of birth, while Model 4 adjust for birth order as well as birth year, giving what we describe as the partial effect of parental age. 
*** Figure 5 Approximately Here ${ }^{* * *}$

The results from Model 3 for all-cause mortality, presented in Table 4 and Figure 5(a), show that the relationship between maternal age at the time of birth and all-cause is flat up to age $35-39$, which is where the vast majority of births take place. However, individuals born to mothers aged $40-44$ have mortality that is $7 \%$ higher, and individuals born to mother aged 45 or older have mortality that is $15 \%$ higher than individuals born to mothers aged 25-29, though these estimates are not statistically significant. An increase in mortality of $7 \%$ is approximately equivalent to an $\mathrm{e}_{30} 8$ months shorter in comparison to those born to women aged 25-29 when applied to a Swedish life table from 2007. This difference in remaining life expectancy at age 30 is slightly larger than seasonal differences in mortality observed in Austria (Doblhammer and Vaupel, 2001). Although the 15\% increase in mortality associated with being born to a mother aged 45 or older is larger, this is only experienced by a very small fraction of the population. The results for paternal age show that being born to teenage father is associated with a $14 \%$ increase in the hazard of mortality, but that increasing paternal age is associated with a monotonic decrease in offspring longevity up to age 54 , at which point there is a small increase. For the most part this decline in mortality is statistically significant. These results indicate that delaying childbearing to older ages has few if any negative consequences for the children of the vast majority of women, and that when men delay childbearing to older ages they actually decrease mortality amongst their children. 
Table 4 and Figure 5(a) also present the results from analyses examining the relationship between parental age at the time of birth and mortality attributable to neoplasms. In Model 3 it is clear that increasing maternal age is not associated with an substantive or statistically significant change in mortality attributable to neoplasms, even at the oldest ages. The results for paternal age are similar to the results for allcause mortality in that they show a clear monotonic decline in mortality for individuals born to older fathers, and that this decline is generally statistically significant. The results from models estimating the relationship between parental age at the time of birth and mortality attributable to cardiovascular diseases can also be seen in Table 4 and Figure 5(a). As with the results for neoplasms, increasing maternal age is not associated with any meaningful change in the mortality attributable to cardiovascular diseases amongst the offspring. The results for paternal age show that being born to a teenage father is associated with a hazard of mortality $36 \%$ higher than the reference category, but those born to older fathers generally have lower mortality from cardiovascular diseases. The results for mortality attributable to all other causes shows an increase in mortality with increasing maternal age and that this is statistically significant, while increasing paternal age is not associated with any great change in the hazard of mortality from other causes of death.

\footnotetext{
*** Table 5 Approximately Here ${ }^{* * *}$
}

The results from Model 4 for all-cause mortality are shown in Table 4 and Figure 5(b). Model 4 includes control variables for the birth year of the index person using 
individual-year dummy variables. As stated in the statistical methods section of this manuscript, we advise caution in the interpretation of these results. Within a sibling group, a one-year increase in maternal or paternal age is exactly the same as a one-year increase in birth year. As a consequence, it should not be possible to pick apart the difference in the effect of maternal age and birth year. Nevertheless, these estimates do suggest what would be expected theoretically: controlling away the benefit of being born into a later birth year means that being born at a later parental age is associated with worse mortality outcomes. The results for all-cause mortality show an increase in mortality with increasing maternal age at the time of birth, and this increase is generally statistically significant. Relative to individuals born to mothers aged 25-29, those born to women aged $40-44$ had a hazard of mortality $15 \%$ higher. This pattern is also consistent across the results from the models examining cause-specific mortality; in each case, mortality amongst the offspring increases with increasing maternal age after age 25-29. The results for paternal age do not show any statistically significant results for all-cause mortality of the cause-specific mortality analyses. For all-cause mortality the point estimates are flat between ages $20-24$ and $45-49$, and being born at a later point in time is not associated with lower mortality as it was in Model 3, shown in Figure $5(a)$

The reader will note that all of our analyses are based upon a pooled analysis of men and women. We tested for an interaction between gender and parental age at the time of birth, and found that there was no statistically significant interaction. We have plotted the estimates from these models and they are shown in the Supplementary Information, in Figures S1 to S3. 


\section{Discussion}

This study has shown that, after taking into account the benefits of being born into a later birth year with lower rates of mortality, in 20th century Sweden postponing fatherhood increased longevity for the offspring, and postponing motherhood had no negative effect. Although previous research has examined the relationship between parental age at childbearing and offspring mortality (Kemkes-Grottenthaler, 2004; Smith et al., 2009; Gavrilov and Gavrilova, 2012; Gillespie et al., 2013), that body of research has focused upon isolating the effect of parental age net of potential confounding factors. This study advances the literature by highlighting the often overlooked point that prospective parents are choosing not just whether to have a child at age 25 or at age 35 , but whether to have a child at age 25 this year or at age 35 a decade from now. We argue that our approach towards understanding the relationship between parental age and offspring mortality represents the most accurate portrayal of that experience from the perspective of any individual mother and father. That is, mothers who delayed childbearing to older ages did not increase the mortality of their children, and fathers who delayed to older ages increased the longevity of their children. While certain risks increase with fertility postponement, such as involuntary childlessness, these results indicate that childrens' longevity increases when childbearing is postponed. Although we focus on mortality over ages 30 to 74 , the low levels of infant, child, and early adult mortality in Sweden mean that the potential impact of mortality selection before age 30 is unlikely to be driving our results.

As shown in Figure 1, life expectancy at birth has been increasing consistently since at least 1900 across a wide range of countries that are today classified as developed. 
Although increases in life expectancy at birth were primarily driven by declines in infant and child mortality in the early part of the 20th century, the more recent improvements have been driven by declines at older ages. As a consequence, we argue that it is extremely plausible that the results that we observe in this study generalize beyond Sweden to other countries where life expectancy has been increasing. It should be added that an increase in the mean age at childbearing at the national level is not needed for our findings to generalize to other contexts, only that life expectancy should be increasing. When life expectancy is increasing, delaying childbearing or continuing childbearing at older ages means that those children will on average live longer than if parents had given birth at an earlier age. As Figure 1 shows, mean age at childbearing for women has also been increasing since the 1970s across a wide range of countries, and the results of our study suggest that, at least in relation to adult mortality, this increase in the age at childbearing should not have any negative consequences for population health.

Considering the consequences of these findings, it may be noted that they have implications for inequality in society more broadly. Indeed, it is possible that these secular improvements in health and longevity are contributing further to the diverging destinies of the children of high socioeconomic and low socioeconomic status parents (McLanahan, 2004). On average, higher maternal age is associated with higher socioeconomic status. If we take two women born in 1950, one of whom comes from a low socioeconomic status background and gives birth at age 20 , and the other of whom comes from a high socioeconomic status background and gives birth at age 40 , even net of the difference in the socioeconomic resources of these two women, the child of the higher SES mother would be expected to live longer. In turn, that means that from a 
parental cohort perspective, the socioeconomic disparities in the health and longevity of children are likely to be even greater than has previously been documented. Furthermore, since there are intergenerational correlations in the timing of childbearing (Kahn and Anderson, 1992; Dahlberg, 2013), this diverging pattern is likely to be cumulative over generations. Indeed a particularly notable dimension of our results is the double-burden of teenage childbearing. While teenage childbearing is associated with a wide range of negative outcomes for offspring (Brooks-Gunn and Furstenberg, 1986), this is particularly true when taking a lifecourse perspective and considering macro-level trends. Not only are the children of teenage parents disadvanted for the all the reasons well enunciated in the previous literature, teenage parents are also giving birth at the point in their lives where their children are least likely to gain from secular improvements in longevity.

This study itself is not without limitations. Due to the nature of the Swedish multigenerational register and the Swedish mortality register, we study mortality over the period 1990-2012 for cohorts born 1938-1960. This means that we observe mortality over different ages for different birth cohorts, and we do not observe mortality before age 30 , or after age 74 . While we would argue that the declines in age-adjusted all-cause and cause-specific mortality (see Figure 2) make it clear that our findings are not limited to the cohorts and ages that we study, we have not been able to empirically evaluate our research question outside of the age range defined by our data structure. Most deaths occur after age 74 in contemporary Sweden, and so the relationship between parental age and offspring longevity may differ when it is possible to study these birth cohorts to extinction. Furthermore, many of our analyses are based upon within-family sibling comparisons. As we describe in the data section, this means that 
our analytical sample is much lower than the size of the full population for those birth cohorts, as the statistical method requires selection upon sibling groups with more than one child, and where at least one sibling has died between 1990 and 2012. Nevertheless, we have also conducted our analyses using data on the full population for whom we can obtain data on parental age at the time of birth, and we find qualitatively very similar results: delaying childbearing to older ages is associated with lower offspring mortality. Indeed, the results are even clearer in the analyses using the full cohort data.

Whether the positive effects of postponement on longevity will continue to be observed in the future depends on whether mortality continues to decline. While the pace of increase in highest period life expectancies may have slowed down, it continues to be positive (Vallin and Meslé, 2009). Moreover, cohort life expectancies have increased even more rapidly than period based measures (Shkolnikov et al., 2011) and most recent trends show that period life expectancy continues to increase year-on-year (Mathers et al., 2015). This suggests that our finding that postponing childbearing increases longevity for offspring not only applies to the cohorts that we examine in this study, but that it applies to cohorts born after 1960, and for cohorts who are born today. Although increases in life expectancy do not always translate directly into increases in healthy life expectancy, healthy life expectancy has also been improving over time (Salomon et al., 2013), suggesting the delaying childbearing to older ages translates into real improvements in the life conditions of the offspring.

Although we have primarily considered the benefits associated with delaying childbearing to older ages, it is also important to reflect on potential disadvantages. From the perspective of parents, delaying childbearing to older ages will on average 
mean that lifespan overlap with their children will be shorter. While a desire to convey as much advantage as possible to children would be natural, this also has to be counterbalanced with wanting to spend more of one's life with one's children. Furthermore, not all secular trends are positive. Although longevity has been increasing consistently over the past century, there have also been increases in inequality (Piketty, 2014), which might have a negative effect on opportunities and life chances. Nevertheless, similar population-level improvements over time are also observed in other domains, including education and cognitive ability (Myrskylä et al., 2013; Barclay and Myrskylä, 2016). Future research on advancing parental age would benefit from combining the traditional microperspective with the macro-perspective outlined in this study that acknowledges the potential benefits of being born at a later date. 


\section{References}

Abdalla, H., Wren, M. and Thomas, A. (1997), 'Age of the uterus does not affect pregnancy or implantation rates; a study of egg donation in women of different ages sharing oocytes from the same donor.', Human Reproduction 12(4), 827-829.

Allison, P. D. (2009), Fixed Effects Regression Models, Vol. 160., SAGE Publications.

Andersen, A.-M. N., Wohlfahrt, J., Christens, P., Olsen, J. and Melbye, M. (2000), 'Maternal age and fetal loss: population based register linkage study', BMJ 320(7251), 1708-1712.

Barclay, K., Keenan, K., Grundy, E., Kolk, M. and Myrskylä, M. (2016), 'Reproductive history and post-reproductive mortality: a sibling comparison analysis using Swedish register data', Social Science \& Medicine 155, 82-92.

Barclay, K. and Kolk, M. (2015), 'Birth order and mortality: a population-based cohort study', Demography 52(2), 613-639.

Barclay, K. and Myrskylä, M. (2014), 'Birth order and physical fitness in early adulthood: Evidence from Swedish military conscription data', Social Science \& Medicine 123, 141148.

Barclay, K. and Myrskylä, M. (2016), 'Advanced maternal age and offspring outcomes: reproductive ageing and counterbalancing period trends', Population and Development Review 42(1), 69-94.

Björck, L., Rosengren, A., Bennett, K., Lappas, G. and Capewell, S. (2009), 'Modelling the decreasing coronary heart disease mortality in Sweden between 1986 and 2002', European Heart Journal 30, 10461056.

Brooks-Gunn, J. and Furstenberg, F. F. (1986), 'The children of adolescent mothers: Physical, academic, and psychological outcomes', Developmental review 6(3), 224-251.

Christensen, K., Doblhammer, G., Rau, R. and Vaupel, J. W. (2009), 'Ageing populations: the challenges ahead', The Lancet 374(9696), 1196-1208.

Cnattingius, S., Forman, M. R., Berendes, H. W. and Isotalo, L. (1992), 'Delayed childbearing and risk of adverse perinatal outcome: a population-based study', Journal of the American Medical Association 268(7), 886-890.

Conde-Agudelo, A., Rosas-Bermúdez, A. and Kafury-Goeta, A. C. (2006), 'Birth spacing and risk of adverse perinatal outcomes: a meta-analysis', JAMA 295(15), 1809-1823.

Cox, D. R. (1972), 'Regression models and life-tables', Journal of the Royal Statistical Society, Series B 34(2), 187-220.

Dahlberg, J. (2013), 'Family influence in fertility: A longitudinal analysis of sibling correlations in first birth risk and completed fertility among Swedish men and women', Demographic Research 29, 233-246. 
Doblhammer, G. and Vaupel, J. W. (2001), 'Lifespan depends on month of birth', Proceedings of the National Academy of Sciences 98(5), 2934-2939.

Drefahl, S., Ahlbom, A. and Modig, K. (2014), 'Losing ground - Swedish life expectancy in a comparative perspective', PloS one 9(2), e88357.

Drefahl, S., Lundström, H., Modig, K. and Ahlbom, A. (2012), 'The era of centenarians: mortality of the oldest old in Sweden', Journal of Internal Medicine 272(1), 100-102.

Gavrilov, L. A. and Gavrilova, N. S. (2012), 'Biodemography of exceptional longevity: early-life and mid-life predictors of human longevity', Biodemography and Social Biology 58(1), 14-39.

Gillespie, D. O., Russell, A. F. and Lummaa, V. (2013), 'The effect of maternal age and reproductive history on offspring survival and lifetime reproduction in preindustrial humans', Evolution 67(7), 1964-1974.

Hart, C. L. and Davey-Smith, G. (2003), 'Relation between number of siblings and adult mortality and stroke risk: 25 year follow up of men in the collaborative study', Journal of Epidemiology and Community Health 57, 385-391.

Hassold, T. and Hunt, P. (2001), 'To err (meiotically) is human: the genesis of human aneuploidy', Nature Reviews Genetics 2(4), 280-291.

Hayward, M. D. and Gorman, B. K. (2004), 'The long arm of childhood: The influence of early-life social conditions on men's mortality', Demography 41(1), 87-107.

Hoffman, S. D., Foster, E. M. and Furstenberg Jr, F. F. (1993), 'Reevaluating the costs of teenage childbearing', Demography 30(1), 1-13.

Hultman, C., Sandin, S., Levine, S., Lichtenstein, P. and Reichenberg, A. (2011), 'Advancing paternal age and risk of autism: new evidence from a population-based study and a metaanalysis of epidemiological studies', Molecular Psychiatry 16(12), 1203-1212.

Human Fertility Database. Max Planck Institute for Demographic Research (Germany) and Vienna Institute of Demography (Austria). Available at www.humanfertility.org (data downloaded 2016-04-15)

Human Mortality Database. University of California, Berkeley (USA), and Max Planck Institute for Demographic Research (Germany). Available at www.mortality.org or www.humanmortality.de (data downloaded on 2016-04-15)

Janssen, F. and Kunst, A. E. (2004), 'ICD coding changes and discontinuities in trends in cause-specific mortality in six European countries, 1950-99', Bulletin of the World Health Organization 82(12), 904-913.

Kahn, J. R. and Anderson, K. E. (1992), 'Intergenerational patterns of teenage fertility', Demography 29(1), 39-57. 
Kalil, A., Ryan, R. and Corey, M. (2012), 'Diverging destinies: maternal education and the developmental gradient in time with children', Demography 49(4), 1361-1383.

Kemkes-Grottenthaler, A. (2004), 'Parental effects on offspring longevity-evidence from 17 th to 19th century reproductive histories', Annals of Human Biology 31(2), 139-158.

Klepinger, D. H., Lundberg, S. and Plotnick, R. D. (1995), 'Adolescent fertility and the educational attainment of young women', Family Planning Perspectives 27, 23-28.

Kong, A., Frigge, M. L., Masson, G., Besenbacher, S., Sulem, P., Magnusson, G., Gudjonsson, S. A., Sigurdsson, A., Jonasdottir, A., Jonasdottir, A. et al. (2012), 'Rate of de novo mutations and the importance of father's age to disease risk', Nature 488(7412), 471475.

La Vecchia, C., Bosetti, C., Lucchini, F., Bertuccio, P., Negri, E., Boyle, P. and Levi, F. (2009), 'Cancer mortality in Europe, 2000-2004, and an overview of trends since 1975', Annals of Oncology 21, 13231360.

Lappegård, T. (2000), 'New fertility trends in Norway', Demographic Research 2, 3.

Mackenbach, J. P., Kunst, A. E., Cavelaars, A. E. J. M., Groenhof, F., Geurts, J. J. M., Studygroup, A. and Gunning-Schepers, L. J. (1997), 'Socioeconomic inequalities in morbidity and mortality in Western Europe', The Lancet 349, 1655-1659.

Mare, R. D. (2016), 'Educational homogamy in two gilded ages evidence from intergenerational social mobility data', The ANNALS of the American Academy of Political and Social Science 663(1), 117-139.

Margolis, R. and Myrskylä M. (2011), 'A global perspective on happiness and fertility', Population and Development Review 37(1), 29-56.

Mathers, C. D., Stevens, G. A., Boerma, T., White, R. A. and Tobias, M. I. (2015), 'Causes of international increases in older age life expectancy', The Lancet 385(9967), 540-548.

McLanahan, S. (2004), 'Diverging destinies: How children are faring under the second demographic transition', Demography 41(4), 607-627.

McPherson, M., Smith-Lovin, L. and Cook, J. M. (2001), 'Birds of a feather: Homophily in social networks', Annual Review of Sociology 27, 415-444.

Modig, K., Andersson, T., Drefahl, S. and Ahlbom, A. (2013), 'Age-specific trends in morbidity, mortality and case-fatality from cardiovascular disease, myocardial infarction and stroke in advanced age: evaluation in the swedish population', PloS one 8(5), e64928.

Myrskylä, M., Elo, I. T., Kohler, I. V. and Martikainen, P. (2014), 'The association between advanced maternal and paternal ages and increased adult mortality is explained by early parental loss', Social Science \& Medicine 119, 215-223. 
Myrskylä, M. and Fenelon, A. (2012), 'Maternal age and offspring adult health: Evidence from the health and retirement study', Demography 49(4), 1231-1257.

Myrskylä, M. and Margolis, R. (2014), 'Happiness: Before and after the kids', Demography 51(5), 1843-1866.

Myrskylä, M., Silventoinen, K., Tynelius, P. and Rasmussen, F. (2013), 'Is later better or worse? association of advanced parental age with offspring cognitive ability among half a million young Swedish men', American Journal of Epidemiology 177(7), 649-655.

Oeppen, J., Vaupel, J. W. et al. (2002), 'Broken limits to life expectancy', Science 296(5570), 1029-1031.

Osler, M., Andersen, A. N., Due, P., Lund, R., Damsgaard, M. T. and Holstein, B. E. (2003), 'Socioeconomic position in early life, birth weight, childhood cognitive function, and adult mortality. a longitudinal study of danish men born in 1953', Journal of Epidemiology and Community Health 57(9), 681-686.

Piketty, T. (2014), Capital in the twenty-first century, Harvard University Press, Cambridge, MA.

Powell, B., Steelman, L. C. and Carini, R. M. (2006), 'Advancing age, advantaged youth: parental age and the transmission of resources to children', Social Forces 84(3), 13591390.

Rocca, W., Van Duijn, C., Clayton, D., Chandra, V., Fratiglioni, L., Graves, A., Heyman, A., Jorm, A., Kokmen, E., Kondo, K. et al. (1991), 'Maternal age and Alzheimer's Disease: a collaborative re-analysis of case-control studies', International Journal of Epidemiology 20(Supplement 2), S21-S27.

Salomon, J. A., Wang, H., Freeman, M. K., Vos, T., Flaxman, A. D., Lopez, A. D. and Murray, C. J. (2013), 'Healthy life expectancy for 187 countries, 1990-2010: a systematic analysis for the global burden disease study 2010', The Lancet 380(9859), 2144-2162.

SCB (2011), Multigeneration Register 2010: A Description of Contents and Quality, Statistics Sweden, Stockholm.

Shkolnikov, V. M., Jdanov, D. A., Andreev, E. M. and Vaupel, J. W. (2011), 'Steep increase in best-practice cohort life expectancy', Population and Development Review 37(3), 419-434.

Sipos, A., Rasmussen, F., Harrison, G., Tynelius, P., Lewis, G., Leon, D. A. and Gunnell, D. (2004), 'Paternal age and schizophrenia: a population based cohort study', BMJ $329(7474), 1070$.

Smith, K. R., Mineau, G. P., Garibotti, G. and Kerber, R. (2009), 'Effects of childhood and middle-adulthood family conditions on later-life mortality: evidence from the Utah Population Database, 1850-2002', Social Science and Medicine 68, 1649-1658. 
Socialstyrelsen (2007), Dödsorsaker 2005 [Causes of Death 2005], Socialstyrelsen, Stockholm, Sweden.

Socialstyrelsen (2013), Dödsorsaker 2013 [Causes of Death 2013], Socialstyrelsen, Stockholm, Sweden.

Tatone, C., Amicarelli, F., Carbone, M. C., Monteleone, P., Caserta, D., Marci, R., Artini, P. G., Piomboni, P. and Focarelli, R. (2008), 'Cellular and molecular aspects of ovarian follicle ageing', Human Reproduction Update 14(2), 131-142.

Thomson, E., Lappegård, T., Carlson, M., Evans, A. and Gray, E. (2014), 'Childbearing across partnerships in australia, the united states, norway, and sweden', Demography 51(2), 485-508.

Torssander, J. and Erikson, R. (2010), 'Stratification and mortality - a comparison of education, class, status, and income', European Sociological Review 26(4), 465-474.

UN (2014), World Fertility Report 2013: Fertility at the Extremes, United Nations, Department of Economic and Social Affairs, Population Division, New York, NY.

Vallin, J. and Meslé, F. (2009), 'The segmented trend line of highest life expectancies', Population and Development Review 35(1), 159-187.

Yip, B. H., Pawitan, Y. and Czene, K. (2006), 'Parental age and risk of childhood cancers: a population-based cohort study from Sweden', International Journal of Epidemiology 35(6), 1495-1503. 


\section{Figures}

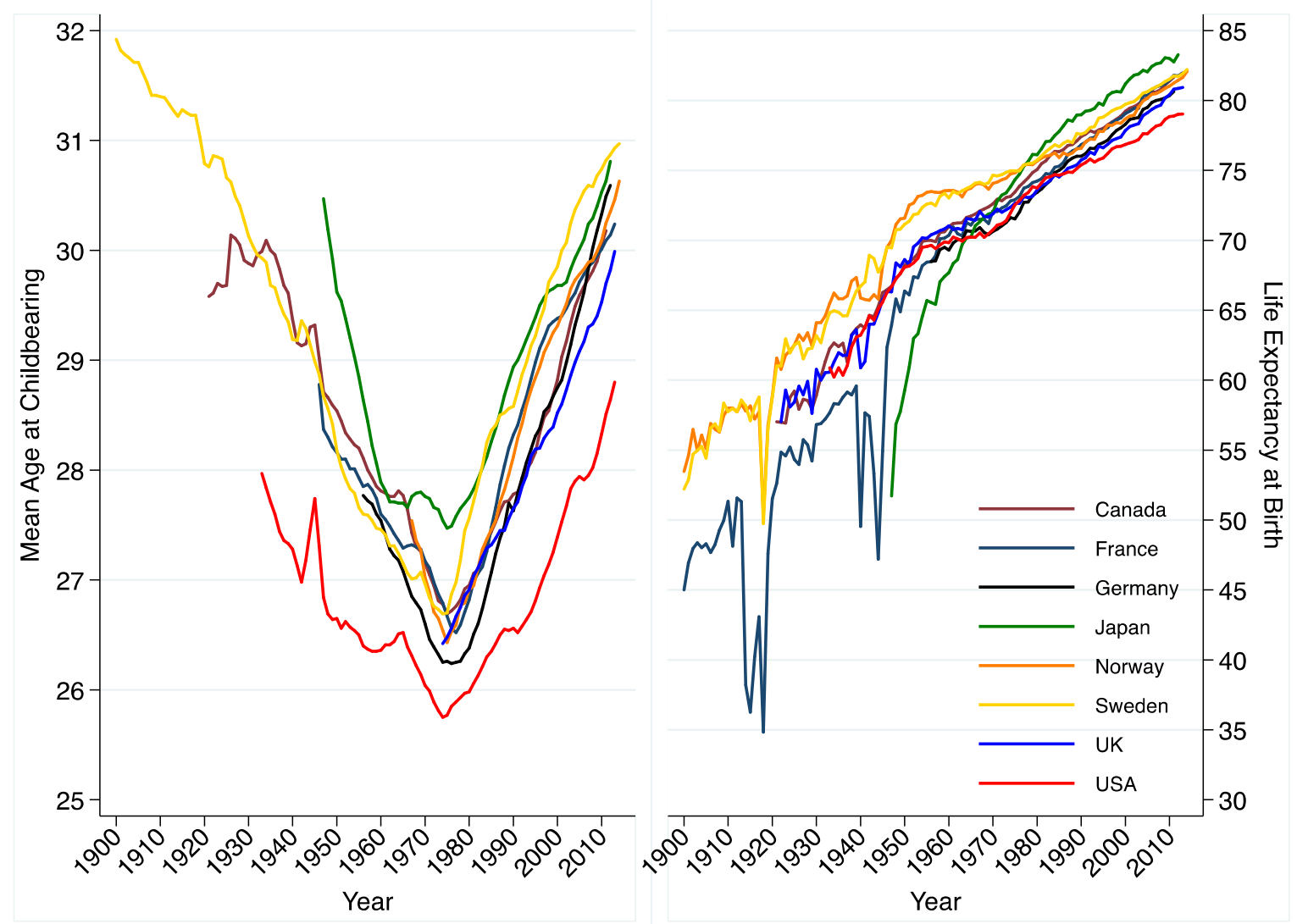

FIGURE 1. Mean Age at Childbearing Amongst Women, and Life Expectancy at Birth for Men and Women Combined in Various Developed Countries, 1900-2014 Dependent Upon Data Availability. Note: Life Expectancy at Birth in Germany Refers to West Germany. Sources: Human Fertility Database and Human Mortality Database. 


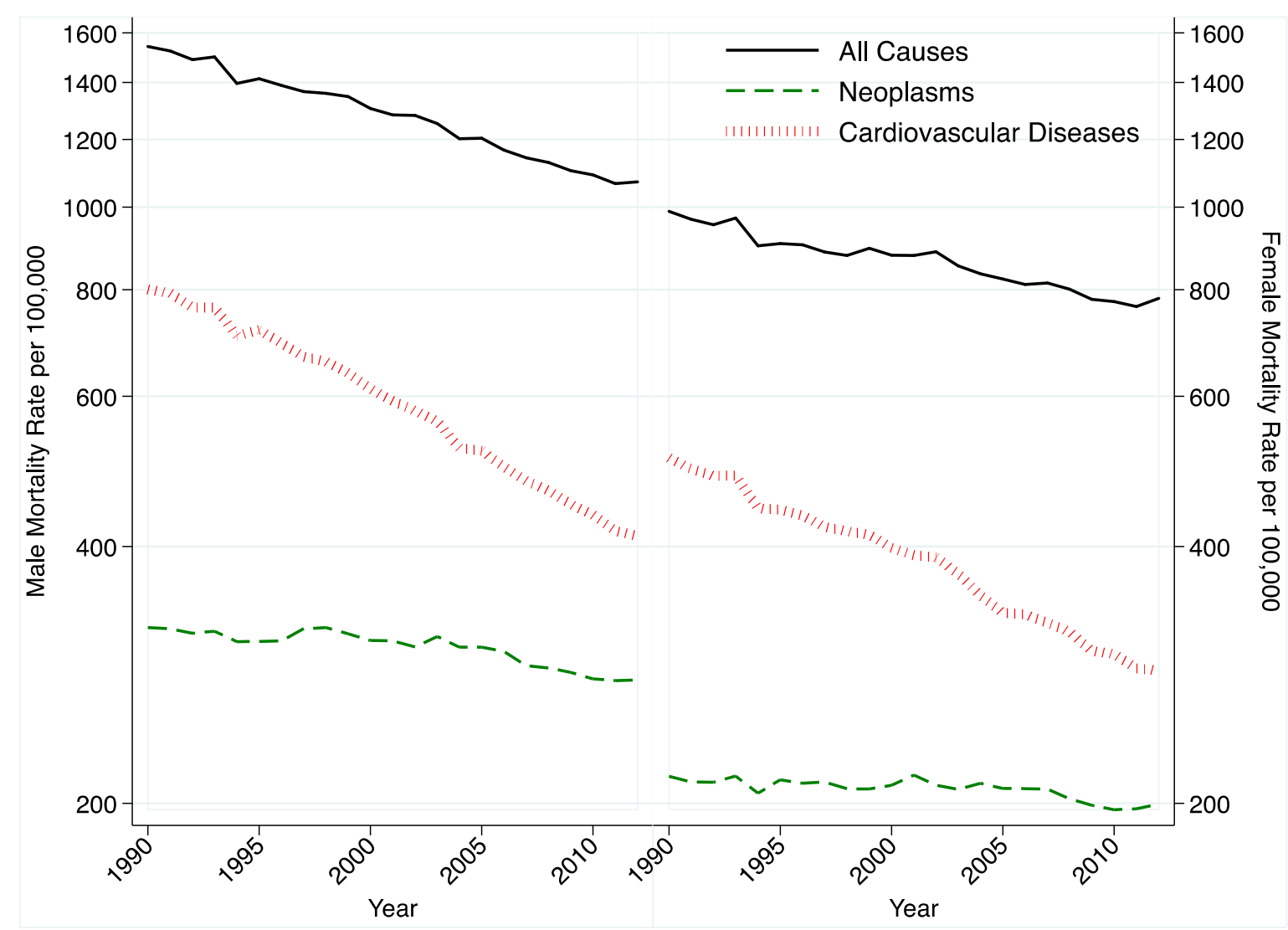

FIGURE 2. Age-adjusted Period Mortality Rates for Major Causes of Death for Swedish Men and Women, 1990-2012. Sources: Socialstyrelsen [Swedish National Board of Health and Welfare] $(2007,2014)$. 

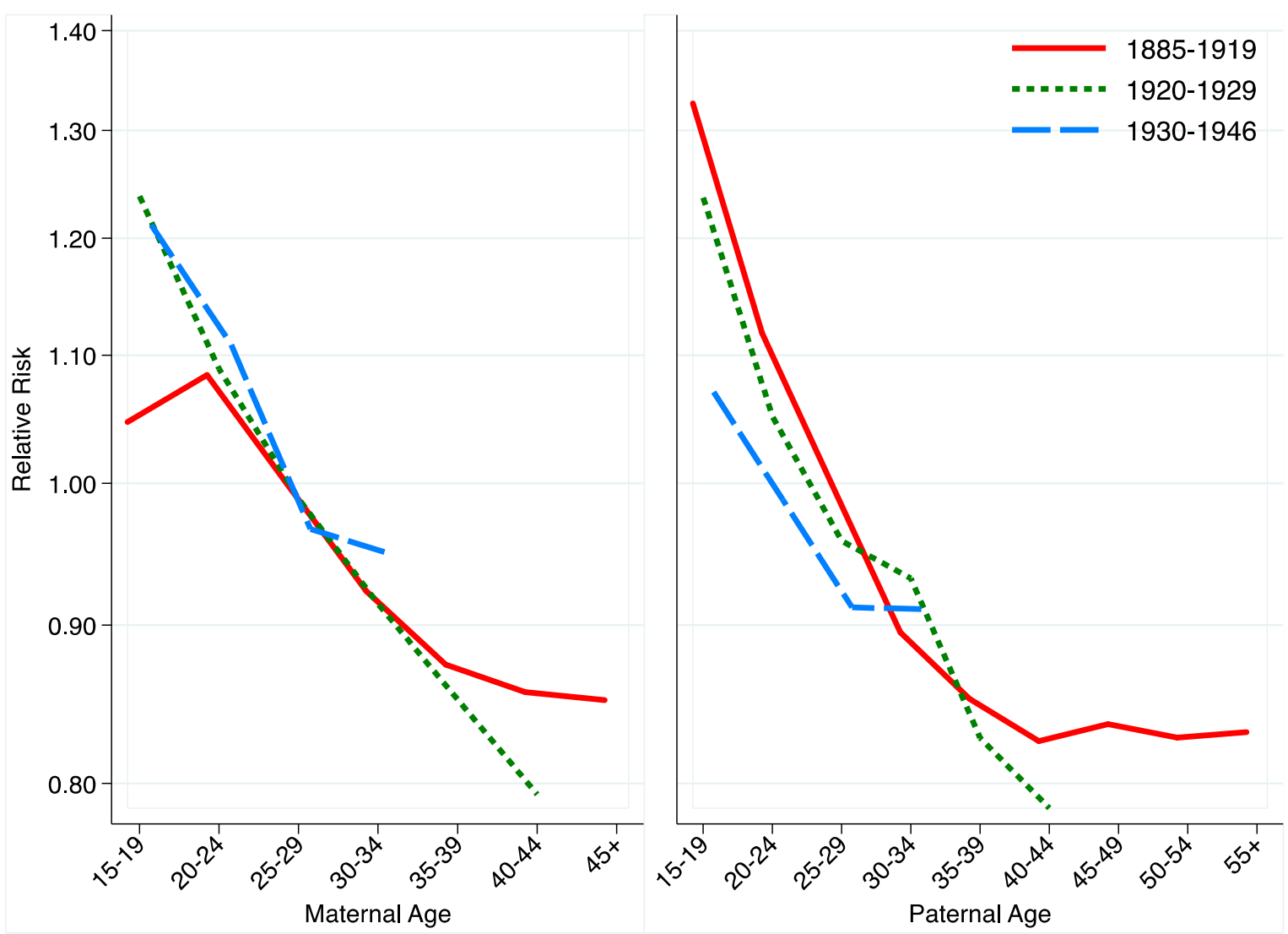

FIGURE 3. All-cause Mortality for Swedish Men and Women by Parental Birth Cohort: Full 1938-1960 Cohort; Between-family Analysis of Maternal and Paternal Age at the Time of Birth. 

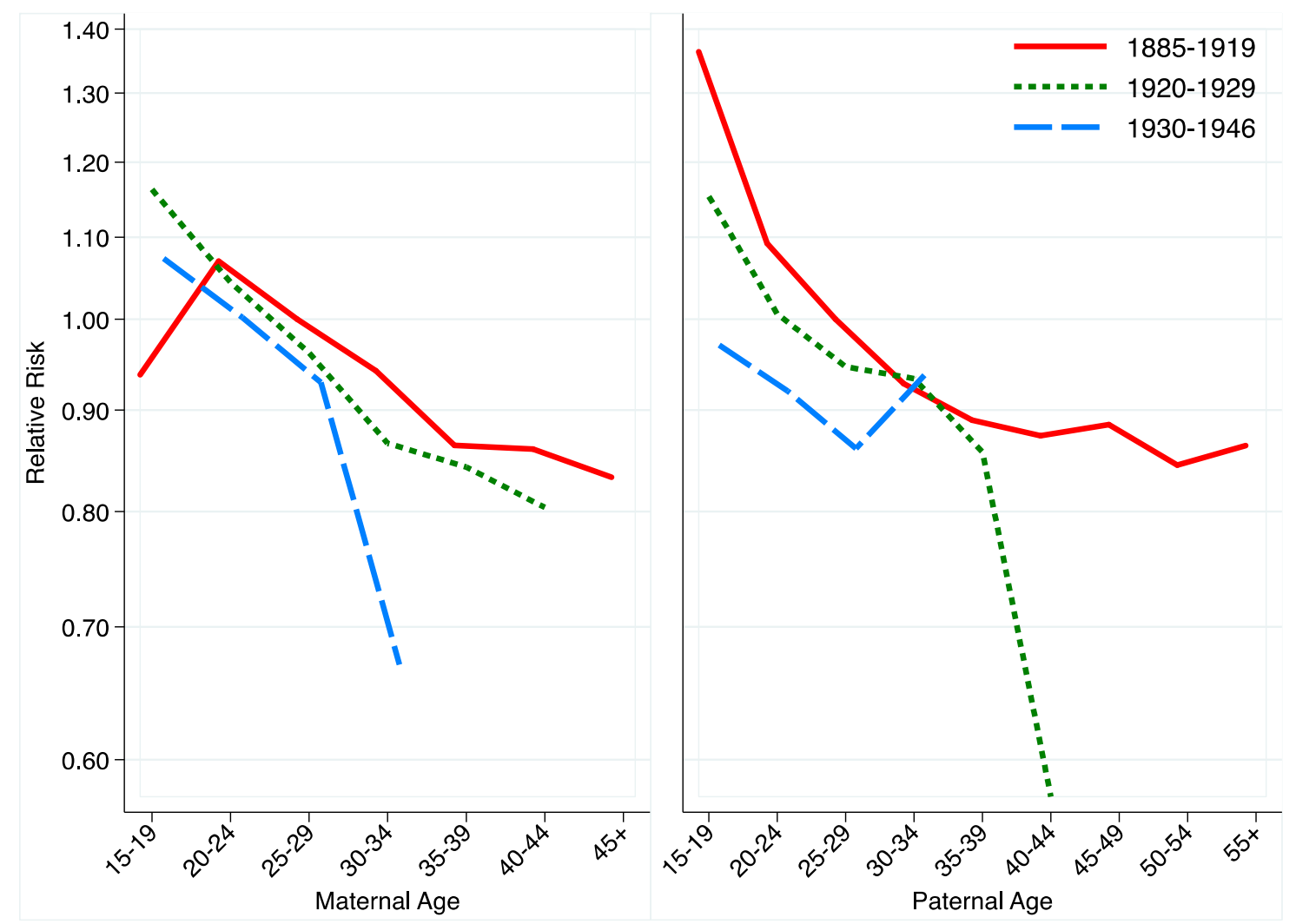

(a) Mortality Attributable to Neoplasms
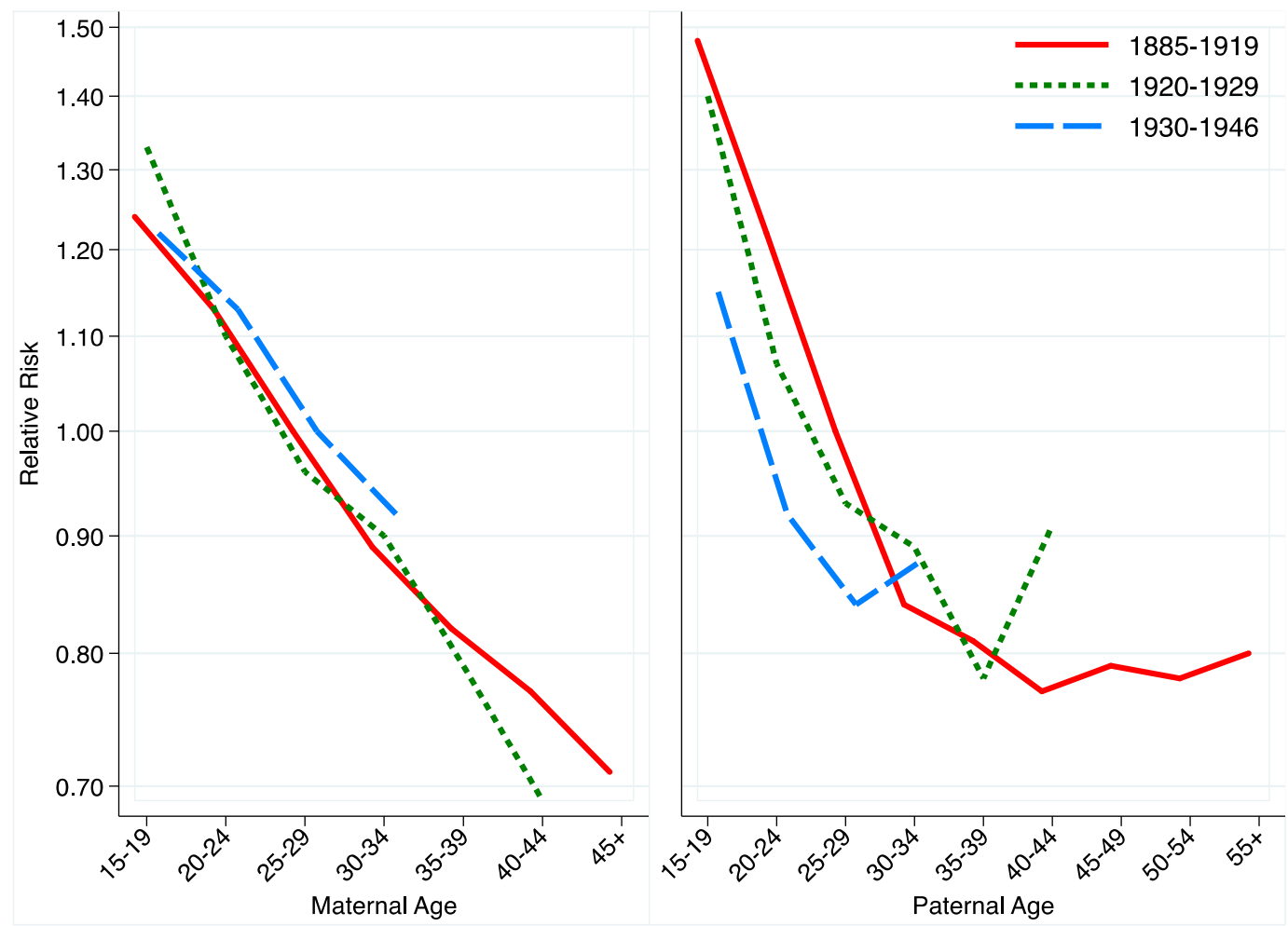

(b) Mortality Attributable to Cardiovascular Diseases

(c)

FIGURE 4. Cause-specific Mortality for Swedish Men and Women by Parental Birth Cohort: Full 1938-1960 Cohort; Between-family Analysis of Maternal and Paternal Age at the Time of Birth. 

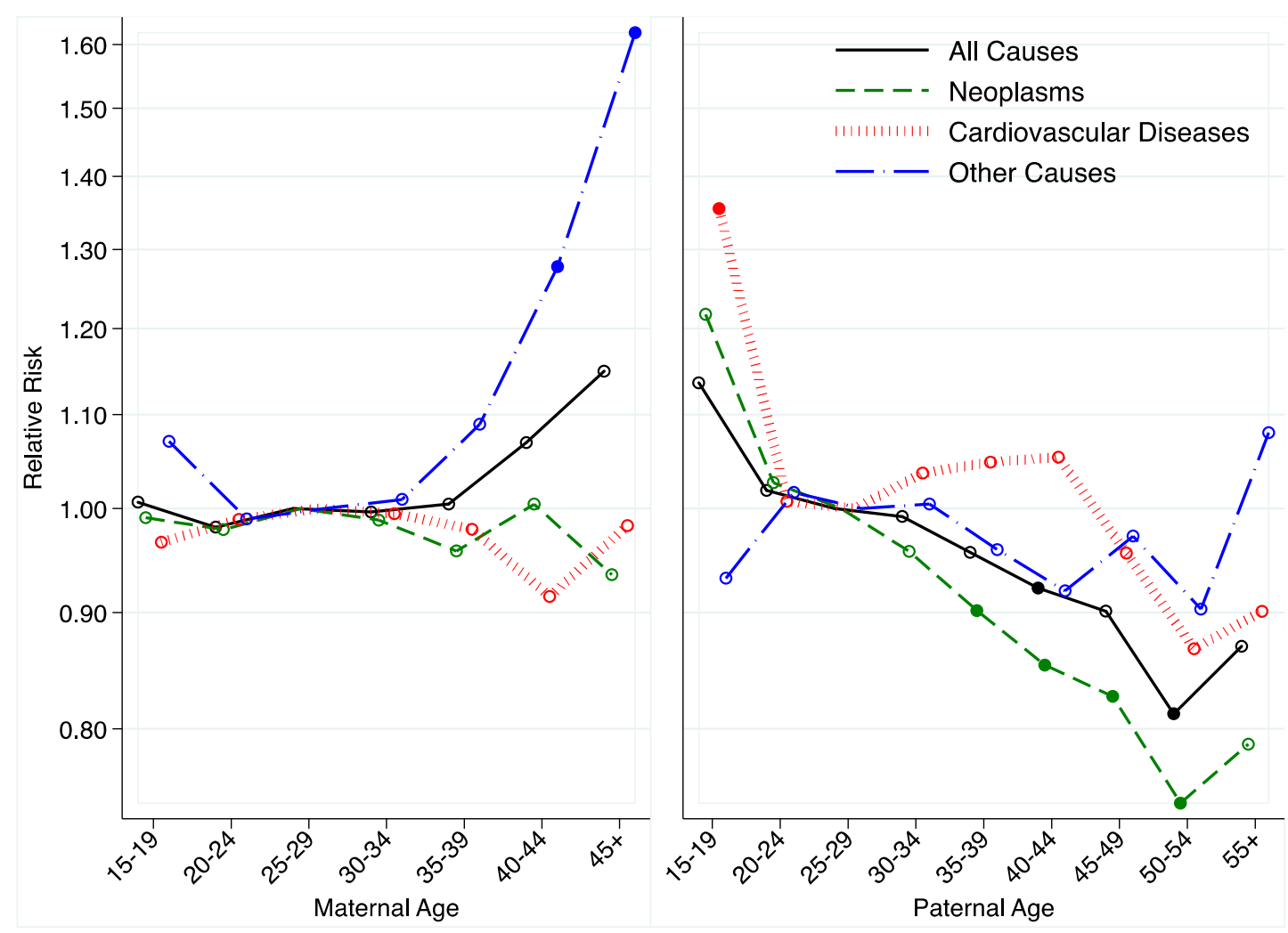

(a) Results from Model 3 for Total Effect of Parental Age
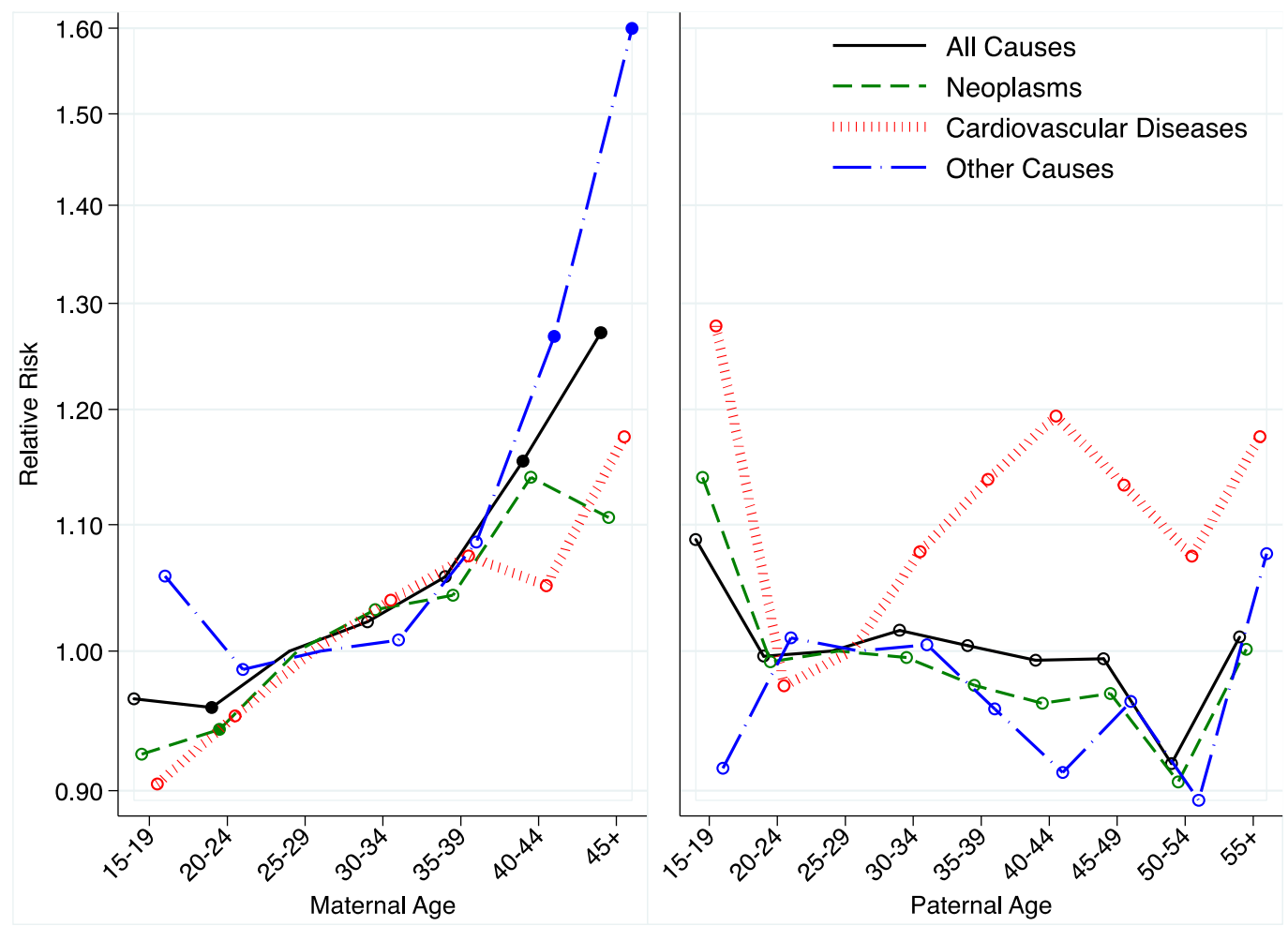

(b) Results from Model 4 for Partial Effect of Parental Age

FIGURE 5. Maternal and Paternal Age at the Time of Birth and Mortality Attributable to All-causes, Neoplasms, Cardiovascular Diseases, and All Remaining Other Causes for Swedish Men andWomen Born 1938-1960. Error Bars are 95\% Confidence Intervals. Note: Hollow Data Points Indicate Lack of Statistical Significance, While Filled Data Points Indicate That the Point Estimate is Statistically Significant. 


\section{Tables}

TABLE 1. Descriptives: Full Cohort and Sibling Sample for Swedish Men and Women Born 1938-1960 Full Cohort Sibling Sample

\begin{tabular}{|c|c|c|c|c|c|c|c|}
\hline & & Person-time (\%) & Deaths & Rate $\left(10^{-4}\right)$ & Person-time (\%) & Deaths & Rate $\left(10^{-4}\right)$ \\
\hline \multirow[t]{7}{*}{ Maternal Age } & $15-19$ & 3.9 & 6,323 & 3.2 & 3.2 & 4,815 & 19.9 \\
\hline & $20-24$ & 23.1 & 36,523 & 3.1 & 21.1 & 29,210 & 18.2 \\
\hline & $25-29$ & 30.5 & 46,777 & 3.0 & 29.7 & 37,134 & 16.4 \\
\hline & $30-34$ & 23.8 & 37,259 & 3.1 & 25.2 & 27,387 & 14.3 \\
\hline & $35-39$ & 13.7 & 22,057 & 3.2 & 15.3 & 14,193 & 12.2 \\
\hline & $40-44$ & 4.6 & 7,694 & 3.3 & 5.1 & 4,125 & 10.5 \\
\hline & $45+$ & 0.4 & 695 & 3.4 & 0.4 & 305 & 9.2 \\
\hline \multirow[t]{9}{*}{ Paternal Age } & $15-19$ & 0.6 & 1,015 & 3.2 & 0.4 & 675 & 21.8 \\
\hline & $20-24$ & 11.1 & 17,384 & 3.1 & 9.1 & 13,234 & 19.2 \\
\hline & $25-29$ & 26.1 & 40,611 & 3.1 & 24.0 & 32,207 & 17.6 \\
\hline & $30-34$ & 27.6 & 42,940 & 3.1 & 27.4 & 33,097 & 15.8 \\
\hline & $35-39$ & 19.3 & 30,531 & 3.1 & 21.0 & 21,922 & 13.7 \\
\hline & $40-44$ & 10.0 & 16,189 & 3.2 & 11.7 & 10,697 & 12.0 \\
\hline & $45-49$ & 3.8 & 6,391 & 3.3 & 4.6 & 3,955 & 11.2 \\
\hline & $50-54$ & 1.1 & 1,836 & 3.4 & 1.4 & 1,091 & 10.5 \\
\hline & $55+$ & 0.3 & 431 & 2.9 & 0.4 & 291 & 10.6 \\
\hline \multirow[t]{2}{*}{ Sex } & Male & 50.8 & 95,679 & 3.7 & 52.6 & 71,414 & 17.8 \\
\hline & Female & 49.2 & 61,649 & 2.5 & 47.4 & 45,755 & 12.7 \\
\hline \multirow[t]{7}{*}{ Birth Order } & 1 & 47.4 & 79,301 & 3.3 & 27.6 & 47,277 & 22.5 \\
\hline & 2 & 31.5 & 47,293 & 3.0 & 32.5 & 40,743 & 16.4 \\
\hline & 3 & 12.9 & 18,915 & 2.9 & 20.0 & 17,544 & 11.5 \\
\hline & 4 & 4.8 & 6,994 & 2.9 & 10.2 & 6,797 & 8.7 \\
\hline & 5 & 1.9 & 2,789 & 2.9 & 4.9 & 2,773 & 7.4 \\
\hline & 6 & 0.8 & 1,119 & 2.8 & 2.4 & 1,118 & 6.2 \\
\hline & $7+$ & 0.7 & 917 & 2.8 & 2.4 & 917 & 5.0 \\
\hline \multirow[t]{4}{*}{ Birth Year } & 1938-1944 & 26.3 & 75,165 & 5.7 & 34.7 & 52,726 & 19.9 \\
\hline & $1945-1949$ & 25.1 & 41,874 & 3.3 & 29.5 & 33,118 & 14.8 \\
\hline & $1950-1954$ & 22.5 & 23,645 & 2.1 & 20.8 & 19,506 & 12.3 \\
\hline & $1955-1960$ & 26.2 & 16,644 & 1.3 & 15.0 & 11,819 & 10.4 \\
\hline \multirow[t]{4}{*}{ Mother Vital Status } & Alive, In Sweden & 58.4 & 54,886 & 1.9 & & & \\
\hline & Outmigrated & 0.3 & 352 & 2.1 & & & \\
\hline & Dead & 41.2 & 101,941 & 4.9 & & & \\
\hline & Outmigrated, and Dead & 0.1 & 149 & 4.3 & & & \\
\hline \multirow[t]{4}{*}{ Father Vital Status } & Alive, In Sweden & 36.8 & 27,547 & 1.5 & & & \\
\hline & Outmigrated & 0.5 & 528 & 2.2 & & & \\
\hline & Dead & 62.6 & 128,920 & 4.1 & & & \\
\hline & Outmigrated, and Dead & 0.2 & 333 & 3.7 & & & \\
\hline
\end{tabular}


TABLE 2. Full Cohort Between-family Analyses of Swedish Men and Women Born 19381960: All-cause Mortality and Mortality Attributable to Neoplasms Over the Period 1990-2012.

\begin{tabular}{|c|c|c|c|c|c|c|c|c|c|}
\hline \multicolumn{10}{|c|}{ All-cause Mortality } \\
\hline \multirow[b]{3}{*}{ Maternal Age } & & \multicolumn{2}{|c|}{ Model 1} & \multicolumn{2}{|c|}{ Model 2} & \multicolumn{2}{|c|}{ Model 1} & \multicolumn{2}{|c|}{ Model 2} \\
\hline & & RR & $95 \%$ CI & $\mathrm{RR}$ & $95 \% \mathrm{CI}$ & \multicolumn{2}{|c|}{ 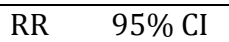 } & \multirow{2}{*}{$\begin{array}{c}\text { RR } \\
1.13\end{array}$} & $95 \% \mathrm{CI}$ \\
\hline & $15-19$ & 1.13 & $1.10-1.17$ & 1.22 & $1.18-1.25$ & 1.08 & $1.03-1.13$ & & $1.08-1.18$ \\
\hline & $20-24$ & 1.05 & $1.03-1.07$ & 1.10 & $1.08-1.11$ & 1.03 & $1.01-1.06$ & 1.06 & $1.03-1.08$ \\
\hline & $25-29$ & 1.00 & & 1.00 & & 1.00 & & 1.00 & \\
\hline & $30-34$ & 1.00 & $0.99-1.01$ & 0.93 & $0.91-0.94$ & 1.00 & $0.98-1.02$ & 0.94 & $0.92-0.97$ \\
\hline & $35-39$ & 1.02 & $1.00-1.04$ & 0.88 & $0.86-0.90$ & 0.98 & $0.95-1.01$ & 0.88 & $0.85-0.91$ \\
\hline & $40-44$ & 1.05 & $1.02-1.08$ & 0.86 & 0.83-0.89 & 1.01 & 0.97-1.06 & 0.87 & $0.83-0.92$ \\
\hline & $45+$ & 1.07 & $0.99-1.16$ & 0.86 & $0.79-0.93$ & 1.00 & $0.88-1.13$ & 0.85 & $0.75-0.96$ \\
\hline \multirow[t]{9}{*}{ Paternal Age } & $15-19$ & 1.13 & $1.06-1.21$ & 1.20 & $1.12-1.28$ & 1.08 & $0.98-1.20$ & 1.12 & $1.01-1.24$ \\
\hline & $20-24$ & 1.05 & $1.03-1.07$ & 1.08 & $1.06-1.10$ & 1.02 & $0.99-1.05$ & 1.04 & $1.01-1.07$ \\
\hline & $25-29$ & 1.00 & & 1.00 & & 1.00 & & 1.00 & \\
\hline & $30-34$ & 0.98 & $0.97-1.00$ & 0.92 & $0.91-0.94$ & 1.00 & $0.97-1.02$ & 0.95 & $0.93-0.97$ \\
\hline & $35-39$ & 0.99 & $0.97-1.01$ & 0.87 & $0.85-0.89$ & 0.99 & $0.97-1.02$ & 0.91 & $0.88-0.93$ \\
\hline & $40-44$ & 1.00 & $0.98-1.02$ & 0.84 & $0.82-0.87$ & 1.00 & 0.97-1.04 & 0.89 & $0.86-0.92$ \\
\hline & $45-49$ & 1.03 & $1.00-1.07$ & 0.86 & $0.83-0.88$ & 1.03 & $0.98-1.08$ & 0.90 & $0.86-0.95$ \\
\hline & $50-54$ & 1.04 & 0.98-1.09 & 0.85 & $0.80-0.89$ & 0.99 & 0.91-1.07 & 0.86 & $0.79-0.93$ \\
\hline & $55+$ & 1.07 & $0.97-1.18$ & 0.85 & $0.77-0.94$ & 1.03 & $0.88-1.20$ & 0.88 & $0.75-1.03$ \\
\hline \multirow[t]{2}{*}{ Sex } & Male & 1.00 & & 1.00 & & 1.00 & & 1.00 & \\
\hline & Female & 0.66 & $0.65-0.66$ & 0.66 & $0.65-0.66$ & 1.07 & $1.05-1.08$ & 1.06 & $1.05-1.08$ \\
\hline Birth Order & 1 & & & 1.00 & & & & 1.00 & \\
\hline & 2 & & & 1.03 & $1.02-1.05$ & & & 1.04 & $1.01-1.06$ \\
\hline & 3 & & & 1.08 & $1.05-1.10$ & & & 1.08 & $1.04-1.12$ \\
\hline & 4 & & & 1.06 & $1.03-1.10$ & & & 1.04 & 0.99-1.09 \\
\hline & 5 & & & 1.11 & $1.06-1.16$ & & & 1.09 & $1.02-1.17$ \\
\hline & 6 & & & 1.12 & $1.05-1.20$ & & & 1.13 & $1.02-1.25$ \\
\hline & $7+$ & & & 1.20 & $1.11-1.30$ & & & 1.31 & $1.16-1.47$ \\
\hline Sibling Group Size & 1 & & & 1.16 & $1.14-1.18$ & & & 1.08 & $1.06-1.11$ \\
\hline & 2 & & & 1.00 & & & & 1.00 & \\
\hline & 3 & & & 0.97 & $0.96-0.98$ & & & 0.97 & $0.95-0.99$ \\
\hline & 4 & & & 0.99 & $0.98-1.01$ & & & 0.99 & $0.96-1.02$ \\
\hline & 5 & & & 1.04 & $1.01-1.06$ & & & 1.02 & 0.99-1.06 \\
\hline & 6 & & & 1.02 & 0.98-1.05 & & & 0.99 & $0.95-1.05$ \\
\hline & $7+$ & & & 1.02 & $0.99-1.06$ & & & 1.02 & $0.97-1.08$ \\
\hline Birth Interval & & & & 1.00 & $1.00-1.00$ & & & 1.00 & $1.00-1.00$ \\
\hline Maternal Education & Primary (<9 years) & & & 1.06 & $1.04-1.08$ & & & 1.03 & $1.01-1.06$ \\
\hline & Primary ( 9 years) & & & 1.04 & $1.00-1.08$ & & & 0.98 & $0.94-1.02$ \\
\hline & Secondary (10-11 years) & & & 1.00 & & & & 1.00 & \\
\hline & Secondary (12 years) & & & 0.98 & $0.96-1.01$ & & & 0.92 & $0.85-1.00$ \\
\hline & Tertiary (13-15 years) & & & 0.95 & $0.91-1.00$ & & & 0.86 & $0.79-0.93$ \\
\hline & Tertiary $(15+$ years $)$ & & & 0.93 & $0.89-0.97$ & & & 0.88 & $0.82-0.95$ \\
\hline & Post-graduate & & & 0.96 & $0.86-1.07$ & & & 0.90 & $0.58-1.40$ \\
\hline & Missing & & & 1.14 & $1.12-1.17$ & & & 1.11 & 1.07-1.15 \\
\hline Paternal Education & Primary (<9 years) & & & 1.04 & $1.03-1.06$ & & & 1.03 & $1.00-1.06$ \\
\hline & Primary ( 9 years) & & & 0.96 & 0.94-0.99 & & & 1.01 & $0.96-1.08$ \\
\hline & Secondary (10-11 years) & & & 1.00 & & & & 1.00 & \\
\hline & Secondary (12 years) & & & 0.95 & $0.91-1.00$ & & & 0.97 & $0.93-1.01$ \\
\hline & Tertiary (13-15 years) & & & 0.85 & $0.81-0.89$ & & & 0.94 & $0.88-1.00$ \\
\hline & Tertiary (15+ years) & & & 0.87 & $0.83-0.91$ & & & 0.93 & 0.88-0.99 \\
\hline & Post-graduate & & & 0.87 & $0.65-1.16$ & & & 0.95 & $0.80-1.13$ \\
\hline & Missing & & & 1.10 & $1.08-1.13$ & & & 1.10 & $1.06-1.13$ \\
\hline Mother Vital Status & Alive, In Sweden & & & 1.00 & & & & 1.00 & \\
\hline & Outmigrated & & & 1.07 & $0.96-1.20$ & & & 1.16 & $0.97-1.39$ \\
\hline & Dead & & & 1.33 & $1.32-1.35$ & & & 1.17 & $1.15-1.20$ \\
\hline & Outmigrated, and Dead & & & 1.14 & $0.96-1.35$ & & & 1.27 & $1.00-1.61$ \\
\hline Father Vital Status & Alive, In Sweden & & & 1.00 & & & & 1.00 & \\
\hline & Outmigrated & & & 1.28 & $1.17-1.40$ & & & 1.00 & $0.85-1.17$ \\
\hline & Dead & & & 1.28 & $1.26-1.30$ & & & 1.14 & $1.11-1.17$ \\
\hline & Outmigrated, and Dead & & & 1.33 & $1.19-1.49$ & & & 1.10 & $0.92-1.31$ \\
\hline $\mathrm{N}$ & & & 99,314 & & 99,314 & & 99,314 & & 99,314 \\
\hline Deaths & & & 7,328 & & 7,328 & & 6,246 & & 6,246 \\
\hline
\end{tabular}


TABLE 3. Full Cohort Between-family Analyses of Swedish Men and Women Born 19381960: Mortality Attributable to Cardiovascular Diseases and Mortality Attributable to All Other Causes Over the Period 1990-2012.

\begin{tabular}{|c|c|c|c|c|c|c|c|c|c|}
\hline \multirow{4}{*}{ Maternal Age } & & \multicolumn{4}{|c|}{ Vascular Diseases } & \multicolumn{4}{|c|}{ All Remaining Causes } \\
\hline & & \multicolumn{2}{|c|}{ Model 1} & \multicolumn{2}{|c|}{ Model 2} & \multicolumn{2}{|c|}{ Model 1} & \multicolumn{2}{|c|}{ Model 2} \\
\hline & & RR & $95 \% \mathrm{CI}$ & RR & $95 \%$ CI & RR & $95 \% \mathrm{CI}$ & RR & $95 \% \mathrm{CI}$ \\
\hline & $15-19$ & 1.19 & $1.13-1.26$ & 1.28 & $1.21-1.36$ & 1.16 & $1.10-1.22$ & 1.28 & $1.22-1.35$ \\
\hline & $20-24$ & 1.07 & $1.04-1.10$ & 1.13 & $1.09-1.16$ & 1.06 & $1.03-1.08$ & 1.12 & $1.09-1.15$ \\
\hline & $25-29$ & 1.00 & & 1.00 & & 1.00 & & 1.00 & \\
\hline & $30-34$ & 1.00 & $0.97-1.03$ & 0.91 & $0.88-0.94$ & 1.00 & $0.97-1.02$ & 0.92 & $0.89-0.94$ \\
\hline & $35-39$ & 1.01 & 0.97-1.05 & 0.83 & $0.79-0.86$ & 1.07 & $1.04-1.11$ & 0.92 & $0.88-0.95$ \\
\hline & $40-44$ & 1.01 & $0.96-1.07$ & 0.78 & $0.74-0.84$ & 1.12 & $1.07-1.18$ & 0.91 & $0.86-0.96$ \\
\hline & $45+$ & 0.97 & $0.82-1.14$ & 0.72 & $0.61-0.85$ & 1.25 & $1.10-1.42$ & 0.98 & $0.86-1.11$ \\
\hline \multirow[t]{9}{*}{ Paternal Age } & $15-19$ & 1.23 & 1.09-1.39 & 1.35 & $1.19-1.53$ & 1.12 & $1.00-1.25$ & 1.19 & $1.06-1.32$ \\
\hline & $20-24$ & 1.07 & $1.03-1.11$ & 1.13 & $1.09-1.17$ & 1.06 & $1.02-1.09$ & 1.10 & $1.06-1.13$ \\
\hline & $25-29$ & 1.00 & & 1.00 & & 1.00 & & 1.00 & \\
\hline & $30-34$ & 0.97 & $0.94-1.00$ & 0.88 & $0.85-0.91$ & 0.98 & $0.95-1.00$ & 0.92 & $0.89-0.94$ \\
\hline & $35-39$ & 1.00 & $0.97-1.04$ & 0.83 & $0.80-0.86$ & 0.97 & $0.94-1.00$ & 0.85 & $0.82-0.88$ \\
\hline & $40-44$ & 1.01 & $0.97-1.06$ & 0.79 & $0.75-0.83$ & 0.98 & $0.95-1.02$ & 0.83 & $0.79-0.86$ \\
\hline & $45-49$ & 1.07 & $1.00-1.14$ & 0.81 & $0.76-0.87$ & 1.02 & $0.96-1.07$ & 0.83 & $0.79-0.88$ \\
\hline & $50-54$ & 1.07 & $0.97-1.18$ & 0.80 & $0.73-0.89$ & 1.07 & $0.98-1.16$ & 0.86 & $0.79-0.94$ \\
\hline & $55+$ & 1.15 & $0.95-1.39$ & 0.83 & $0.69-1.01$ & 1.06 & $0.90-1.24$ & 0.83 & $0.70-0.98$ \\
\hline \multirow[t]{2}{*}{ Sex } & Male & 1.00 & & 1.00 & & 1.00 & & 1.00 & \\
\hline & Female & 0.37 & $0.36-0.38$ & 0.37 & $0.36-0.38$ & 0.51 & $0.50-0.52$ & 0.51 & $0.50-0.52$ \\
\hline \multirow[t]{7}{*}{ Birth Order } & 1 & & & 1.00 & & & & 1.00 & \\
\hline & 2 & & & 0.95 & $0.92-0.99$ & & & 1.10 & $1.07-1.14$ \\
\hline & 3 & & & 0.96 & $0.92-1.01$ & & & 1.17 & $1.12-1.21$ \\
\hline & 4 & & & 0.95 & $0.89-1.01$ & & & 1.20 & $1.14-1.27$ \\
\hline & 5 & & & 0.98 & $0.90-1.08$ & & & 1.25 & $1.16-1.35$ \\
\hline & 6 & & & 0.85 & $0.74-0.98$ & & & 1.36 & $1.21-1.52$ \\
\hline & $7+$ & & & 0.91 & $0.78-1.07$ & & & 1.34 & $1.18-1.53$ \\
\hline \multirow[t]{7}{*}{ Sibling Group Size } & 1 & & & 1.20 & $1.16-1.23$ & & & 1.23 & $1.20-1.27$ \\
\hline & 2 & & & 1.00 & & & & 1.00 & \\
\hline & 3 & & & 0.99 & $0.96-1.02$ & & & 0.96 & 0.94-0.98 \\
\hline & 4 & & & 1.04 & $1.00-1.08$ & & & 0.97 & $0.94-1.00$ \\
\hline & 5 & & & 1.09 & $1.04-1.15$ & & & 1.01 & 0.97-1.05 \\
\hline & 6 & & & 1.14 & $1.07-1.22$ & & & 0.95 & $0.89-1.01$ \\
\hline & $7+$ & & & 1.16 & $1.09-1.24$ & & & 0.93 & 0.87-0.99 \\
\hline Birth Interval & & & & 1.00 & $1.00-1.00$ & & & 1.00 & $1.00-1.00$ \\
\hline \multirow{8}{*}{ Maternal Education } & Primary $(<9$ years $)$ & & & 1.10 & $1.06-1.14$ & & & 1.02 & $0.99-1.05$ \\
\hline & Primary ( 9 years) & & & 0.93 & $0.88-0.98$ & & & 0.96 & $0.92-1.01$ \\
\hline & Secondary (10-11 years) & & & 1.00 & & & & 1.00 & \\
\hline & Secondary (12 years) & & & 0.94 & $0.84-1.05$ & & & 1.00 & $0.92-1.08$ \\
\hline & Tertiary (13-15 years) & & & 0.81 & $0.73-0.91$ & & & 0.85 & $0.79-0.92$ \\
\hline & Tertiary $(15+$ years $)$ & & & 0.84 & $0.75-0.94$ & & & 0.87 & $0.80-0.94$ \\
\hline & Post-graduate & & & 0.96 & $0.51-1.79$ & & & 0.79 & $0.48-1.29$ \\
\hline & Missing & & & 1.18 & $1.13-1.23$ & & & 1.04 & $1.00-1.08$ \\
\hline Paternal Education & Primary (< 9 years) & & & 1.15 & $1.10-1.19$ & & & 1.04 & $1.01-1.08$ \\
\hline & Primary ( 9 years) & & & 1.08 & $0.99-1.17$ & & & 1.05 & 0.99-1.12 \\
\hline & Secondary (10-11 years) & & & 1.00 & & & & 1.00 & \\
\hline & Secondary (12 years) & & & 0.99 & 0.93-1.05 & & & 0.99 & $0.95-1.04$ \\
\hline & Tertiary (13-15 years) & & & 0.96 & $0.88-1.05$ & & & 0.97 & $0.91-1.04$ \\
\hline & Tertiary $(15+$ years $)$ & & & 0.88 & $0.80-0.96$ & & & 0.95 & $0.89-1.01$ \\
\hline & Post-graduate & & & 0.92 & $0.71-1.18$ & & & 0.99 & $0.83-1.18$ \\
\hline & Missing & & & 1.28 & $1.23-1.34$ & & & 1.11 & $1.07-1.15$ \\
\hline Mother Vital Status & Alive, In Sweden & & & 1.00 & & & & 1.00 & \\
\hline & Outmigrated & & & 0.74 & $0.55-0.98$ & & & 1.17 & $0.98-1.39$ \\
\hline & Dead & & & 1.53 & $1.49-1.57$ & & & 1.42 & $1.38-1.45$ \\
\hline & Outmigrated, and Dead & & & 1.01 & $0.69-1.46$ & & & 1.07 & $0.79-1.46$ \\
\hline Father Vital Status & Alive, In Sweden & & & 1.00 & & & & 1.00 & \\
\hline & Outmigrated & & & 1.51 & $1.23-1.84$ & & & 1.46 & $1.27-1.68$ \\
\hline & Dead & & & 1.52 & $1.47-1.57$ & & & 1.31 & $1.28-1.35$ \\
\hline & Outmigrated, and Dead & & & 1.50 & $1.18-1.91$ & & & 1.54 & $1.27-1.85$ \\
\hline $\mathrm{N}$ & & & 99,314 & & 99,314 & & 99,314 & & 99,314 \\
\hline Deaths & & & 9,325 & & 9,325 & & 1,757 & & 1,757 \\
\hline
\end{tabular}


TABLE 4. Sibling Population Within-family Comparison Analyses of Swedish Men and Women Born 1938-1960: All-cause Mortality and Mortality Attributable to Neoplasms Over the Period 1990-2012.

\begin{tabular}{|c|c|c|c|c|c|c|c|c|c|}
\hline & & \multicolumn{4}{|c|}{ All-cause Mortality } & \multicolumn{4}{|c|}{ Neoplasms } \\
\hline & & \multicolumn{2}{|c|}{ Model 3} & \multicolumn{2}{|c|}{ Model 4} & \multicolumn{2}{|c|}{ Model 3} & \multicolumn{2}{|c|}{ Model 4} \\
\hline & & $\mathrm{RR}$ & $95 \% \mathrm{CI}$ & $\mathrm{RR}$ & $95 \% \mathrm{CI}$ & $\mathrm{RR}$ & $95 \% \mathrm{CI}$ & $\mathrm{RR}$ & $95 \% \mathrm{CI}$ \\
\hline \multirow[t]{7}{*}{ Maternal Age } & $15-19$ & 1.01 & $0.94-1.08$ & 0.96 & $0.90-1.04$ & 0.99 & $0.89-1.10$ & 0.93 & $0.83-1.04$ \\
\hline & $20-24$ & 0.98 & $0.95-1.01$ & 0.96 & $0.92-0.99$ & 0.98 & $0.93-1.03$ & 0.94 & $0.89-1.00$ \\
\hline & $25-29$ & 1.00 & & 1.00 & & 1.00 & & 1.00 & \\
\hline & $30-34$ & 1.00 & $0.97-1.03$ & 1.02 & $0.99-1.06$ & 0.99 & $0.94-1.04$ & 1.03 & $0.98-1.09$ \\
\hline & $35-39$ & 1.00 & $0.95-1.06$ & 1.06 & $0.99-1.13$ & 0.96 & $0.88-1.04$ & 1.04 & $0.94-1.15$ \\
\hline & $40-44$ & 1.07 & $0.98-1.17$ & 1.15 & $1.04-1.28$ & 1.00 & $0.88-1.15$ & 1.14 & $0.98-1.33$ \\
\hline & $45+$ & 1.15 & $0.95-1.39$ & 1.27 & $1.04-1.56$ & 0.94 & $0.70-1.26$ & 1.11 & $0.81-1.52$ \\
\hline \multirow[t]{9}{*}{ Paternal Age } & $15-19$ & 1.14 & $0.99-1.31$ & 1.09 & $0.94-1.26$ & 1.22 & $0.98-1.52$ & 1.14 & $0.91-1.43$ \\
\hline & $20-24$ & 1.02 & $0.98-1.06$ & 1.00 & $0.95-1.04$ & 1.03 & $0.96-1.09$ & 0.99 & 0.93-1.06 \\
\hline & $25-29$ & 1.00 & & 1.00 & & 1.00 & & 1.00 & \\
\hline & $30-34$ & 0.99 & 0.96-1.02 & 1.02 & $0.98-1.05$ & 0.96 & 0.91-1.01 & 1.00 & $0.94-1.05$ \\
\hline & $35-39$ & 0.96 & $0.91-1.01$ & 1.00 & $0.94-1.07$ & 0.90 & $0.83-0.98$ & 0.97 & 0.89-1.07 \\
\hline & $40-44$ & 0.92 & $0.86-1.00$ & 0.99 & $0.91-1.09$ & 0.85 & $0.76-0.96$ & 0.96 & $0.84-1.11$ \\
\hline & $45-49$ & 0.90 & $0.81-1.00$ & 0.99 & $0.88-1.13$ & 0.83 & $0.70-0.97$ & 0.97 & $0.80-1.17$ \\
\hline & $50-54$ & 0.81 & $0.69-0.95$ & 0.92 & $0.77-1.10$ & 0.74 & $0.58-0.94$ & 0.91 & $0.69-1.19$ \\
\hline & $55+$ & 0.87 & $0.67-1.12$ & 1.01 & $0.77-1.33$ & 0.79 & $0.53-1.16$ & 1.00 & $0.66-1.52$ \\
\hline \multirow[t]{2}{*}{ Sex } & Male & 1.00 & & 1.00 & & 1.00 & & 1.00 & \\
\hline & Female & 0.64 & $0.63-0.66$ & 0.65 & $0.63-0.66$ & 1.11 & $1.08-1.14$ & 1.11 & $1.08-1.14$ \\
\hline \multirow[t]{7}{*}{ Birth Order } & 1 & 1.00 & & 1.00 & & 1.00 & & 1.00 & \\
\hline & 2 & 0.99 & $0.97-1.01$ & 1.00 & $0.98-1.03$ & 0.99 & $0.96-1.02$ & 1.01 & 0.97-1.05 \\
\hline & 3 & 1.01 & $0.97-1.04$ & 1.03 & $0.99-1.07$ & 1.01 & $0.96-1.07$ & 1.05 & $0.98-1.12$ \\
\hline & 4 & 0.98 & $0.93-1.03$ & 1.01 & $0.95-1.07$ & 0.97 & $0.90-1.06$ & 1.03 & $0.93-1.13$ \\
\hline & 5 & 1.00 & $0.94-1.08$ & 1.05 & $0.97-1.13$ & 1.02 & $0.91-1.14$ & 1.09 & $0.96-1.23$ \\
\hline & 6 & 0.99 & $0.90-1.10$ & 1.04 & $0.94-1.16$ & 1.08 & $0.93-1.25$ & 1.16 & $0.99-1.37$ \\
\hline & 7 & 1.09 & $0.97-1.23$ & 1.16 & $1.02-1.31$ & 1.26 & $1.05-1.50$ & 1.38 & $1.14-1.68$ \\
\hline \multirow[t]{23}{*}{ Birth Year } & 1938 & & & 1.00 & & & & 1.00 & \\
\hline & 1939 & & & 1.03 & $0.97-1.08$ & & & 0.98 & $0.90-1.06$ \\
\hline & 1940 & & & 0.99 & $0.94-1.04$ & & & 0.95 & 0.88-1.03 \\
\hline & 1941 & & & 0.95 & $0.90-1.01$ & & & 0.93 & $0.85-1.01$ \\
\hline & 1942 & & & 0.98 & $0.92-1.04$ & & & 0.95 & $0.86-1.05$ \\
\hline & 1943 & & & 0.98 & $0.91-1.05$ & & & 0.96 & $0.86-1.07$ \\
\hline & 1944 & & & 0.97 & $0.90-1.05$ & & & 0.92 & $0.82-1.04$ \\
\hline & 1945 & & & 0.93 & $0.86-1.02$ & & & 0.87 & $0.76-0.99$ \\
\hline & 1946 & & & 0.94 & $0.86-1.03$ & & & 0.87 & $0.75-1.00$ \\
\hline & 1947 & & & 0.90 & $0.81-1.00$ & & & 0.86 & $0.74-1.01$ \\
\hline & 1948 & & & 0.89 & $0.79-0.99$ & & & 0.83 & $0.70-0.99$ \\
\hline & 1949 & & & 0.87 & $0.77-0.99$ & & & 0.79 & $0.66-0.95$ \\
\hline & 1950 & & & 0.88 & $0.77-1.00$ & & & 0.78 & $0.64-0.96$ \\
\hline & 1951 & & & 0.91 & $0.79-1.05$ & & & 0.78 & $0.63-0.97$ \\
\hline & 1952 & & & 0.84 & $0.72-0.97$ & & & 0.72 & $0.57-0.90$ \\
\hline & 1953 & & & 0.83 & $0.71-0.97$ & & & 0.71 & $0.55-0.90$ \\
\hline & 1954 & & & 0.83 & $0.70-0.98$ & & & 0.72 & $0.56-0.93$ \\
\hline & 1955 & & & 0.81 & $0.68-0.97$ & & & 0.69 & $0.53-0.91$ \\
\hline & 1956 & & & 0.83 & $0.69-1.00$ & & & 0.73 & $0.55-0.97$ \\
\hline & 1957 & & & 0.78 & $0.64-0.95$ & & & 0.64 & $0.48-0.87$ \\
\hline & 1958 & & & 0.76 & $0.62-0.93$ & & & 0.64 & $0.46-0.88$ \\
\hline & 1959 & & & 0.72 & $0.58-0.89$ & & & 0.57 & $0.40-0.80$ \\
\hline & 1960 & & & 0.75 & $0.59-0.94$ & & & 0.63 & $0.44-0.90$ \\
\hline \multirow{2}{*}{\multicolumn{2}{|c|}{$\begin{array}{l}\mathrm{N} \\
\text { Deaths }\end{array}$}} & \multirow{2}{*}{\multicolumn{2}{|c|}{$\begin{array}{l}319,749 \\
117,169\end{array}$}} & \multicolumn{2}{|c|}{319,749} & \multirow{2}{*}{\multicolumn{2}{|c|}{$\begin{array}{c}140,601 \\
49,776\end{array}$}} & \multirow{2}{*}{\multicolumn{2}{|c|}{$\begin{array}{c}140,601 \\
49,776\end{array}$}} \\
\hline & & & & & 7,169 & & & & \\
\hline
\end{tabular}


TABLE 5. Sibling Population Within-family Comparison Analyses of Swedish Men and Women Born 1938-1960: Mortality Attributable to Cardiovascular Diseases and Mortality Attributable to All Other Causes Over the Period 1990-2012.

\begin{tabular}{|c|c|c|c|c|c|c|c|c|c|}
\hline & & \multicolumn{4}{|c|}{ Vascular Diseases } & \multicolumn{4}{|c|}{ All Remaining Causes } \\
\hline & & \multicolumn{2}{|c|}{ Model 3} & \multicolumn{2}{|c|}{ Model 4} & \multicolumn{2}{|c|}{ Model 3} & \multicolumn{2}{|c|}{ Model 4} \\
\hline & & $\mathrm{RR}$ & $95 \% \mathrm{CI}$ & $\mathrm{RR}$ & $95 \% \mathrm{CI}$ & 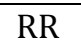 & $95 \% \mathrm{CI}$ & $\mathrm{RR}$ & $95 \% \mathrm{CI}$ \\
\hline \multirow[t]{7}{*}{ Maternal Age } & $15-19$ & 0.97 & $0.84-1.12$ & 0.90 & $0.78-1.06$ & 1.07 & $0.95-1.20$ & 1.06 & $0.93-1.20$ \\
\hline & $20-24$ & 0.99 & $0.92-1.06$ & 0.95 & $0.88-1.03$ & 0.99 & 0.93-1.05 & 0.99 & $0.92-1.05$ \\
\hline & $25-29$ & 1.00 & & 1.00 & & 1.00 & & 1.00 & \\
\hline & $30-34$ & 0.99 & $0.93-1.06$ & 1.04 & $0.96-1.12$ & 1.01 & $0.95-1.07$ & 1.01 & 0.94-1.08 \\
\hline & $35-39$ & 0.98 & $0.87-1.10$ & 1.07 & $0.94-1.23$ & 1.09 & $0.99-1.20$ & 1.09 & $0.97-1.22$ \\
\hline & $40-44$ & 0.91 & $0.76-1.10$ & 1.05 & $0.85-1.30$ & 1.28 & $1.10-1.49$ & 1.27 & $1.06-1.52$ \\
\hline & $45+$ & 0.98 & $0.64-1.51$ & 1.18 & $0.74-1.85$ & 1.62 & $1.17-2.24$ & 1.60 & $1.13-2.27$ \\
\hline \multirow[t]{9}{*}{ Paternal Age } & $15-19$ & 1.36 & $1.00-1.84$ & 1.28 & $0.94-1.74$ & 0.93 & $0.73-1.19$ & 0.92 & $0.72-1.17$ \\
\hline & $20-24$ & 1.01 & $0.93-1.10$ & 0.97 & $0.89-1.07$ & 1.02 & $0.95-1.09$ & 1.01 & 0.94-1.09 \\
\hline & $25-29$ & 1.00 & & 1.00 & & 1.00 & & 1.00 & \\
\hline & $30-34$ & 1.04 & $0.97-1.11$ & 1.08 & $1.00-1.16$ & 1.00 & $0.95-1.06$ & 1.00 & 0.94-1.07 \\
\hline & $35-39$ & 1.05 & $0.94-1.17$ & 1.14 & $1.00-1.30$ & 0.96 & 0.87-1.05 & 0.96 & $0.86-1.07$ \\
\hline & $40-44$ & 1.05 & $0.90-1.24$ & 1.19 & $0.98-1.45$ & 0.92 & $0.80-1.05$ & 0.91 & $0.77-1.07$ \\
\hline & $45-49$ & 0.96 & $0.76-1.20$ & 1.13 & $0.87-1.48$ & 0.97 & $0.81-1.17$ & 0.96 & $0.77-1.21$ \\
\hline & $50-54$ & 0.87 & $0.63-1.20$ & 1.07 & $0.74-1.56$ & 0.90 & $0.68-1.19$ & 0.89 & $0.65-1.23$ \\
\hline & $55+$ & 0.90 & $0.54-1.51$ & 1.18 & $0.67-2.06$ & 1.08 & $0.68-1.72$ & 1.08 & $0.65-1.78$ \\
\hline \multirow[t]{2}{*}{ Sex } & Male & 1.00 & & 1.00 & & 1.00 & & 1.00 & \\
\hline & Female & 0.34 & $0.33-0.36$ & 0.34 & $0.33-0.35$ & 0.48 & $0.46-0.49$ & 0.48 & $0.46-0.49$ \\
\hline \multirow[t]{7}{*}{ Birth Order } & 1 & 1.00 & & 1.00 & & 1.00 & & 1.00 & \\
\hline & 2 & 0.89 & $0.85-0.93$ & 0.92 & $0.87-0.97$ & 1.08 & $1.03-1.12$ & 1.07 & $1.02-1.12$ \\
\hline & 3 & 0.86 & $0.80-0.93$ & 0.91 & $0.84-1.00$ & 1.12 & $1.05-1.20$ & 1.11 & $1.03-1.19$ \\
\hline & 4 & 0.80 & $0.72-0.90$ & 0.87 & $0.77-0.99$ & 1.14 & $1.04-1.26$ & 1.13 & $1.01-1.25$ \\
\hline & 5 & 0.82 & $0.71-0.95$ & 0.90 & $0.77-1.07$ & 1.15 & $1.02-1.31$ & 1.13 & $0.98-1.30$ \\
\hline & 6 & 0.68 & $0.56-0.83$ & 0.76 & $0.61-0.95$ & 1.22 & $1.03-1.44$ & 1.19 & $0.99-1.42$ \\
\hline & 7 & 0.74 & $0.58-0.94$ & 0.84 & $0.65-1.10$ & 1.23 & $1.00-1.52$ & 1.20 & $0.95-1.50$ \\
\hline \multirow[t]{23}{*}{ Birth Year } & 1938 & & & 1.00 & & & & 1.00 & \\
\hline & 1939 & & & 1.00 & $0.90-1.12$ & & & 1.10 & $0.99-1.22$ \\
\hline & 1940 & & & 0.98 & $0.88-1.10$ & & & 1.03 & $0.93-1.15$ \\
\hline & 1941 & & & 0.86 & $0.76-0.97$ & & & 1.06 & $0.95-1.19$ \\
\hline & 1942 & & & 0.91 & $0.80-1.03$ & & & 1.09 & $0.97-1.23$ \\
\hline & 1943 & & & 0.90 & $0.78-1.04$ & & & 1.09 & $0.96-1.25$ \\
\hline & 1944 & & & 0.86 & $0.73-1.01$ & & & 1.16 & $1.01-1.34$ \\
\hline & 1945 & & & 0.83 & $0.70-1.00$ & & & 1.12 & $0.96-1.31$ \\
\hline & 1946 & & & 0.82 & $0.68-1.00$ & & & 1.15 & $0.97-1.36$ \\
\hline & 1947 & & & 0.74 & $0.60-0.92$ & & & 1.07 & $0.89-1.29$ \\
\hline & 1948 & & & 0.77 & $0.61-0.97$ & & & 1.08 & $0.88-1.31$ \\
\hline & 1949 & & & 0.72 & $0.56-0.93$ & & & 1.12 & $0.91-1.39$ \\
\hline & 1950 & & & 0.74 & $0.56-0.97$ & & & 1.15 & $0.92-1.45$ \\
\hline & 1951 & & & 0.79 & $0.59-1.05$ & & & 1.24 & $0.97-1.59$ \\
\hline & 1952 & & & 0.72 & $0.52-0.98$ & & & 1.10 & $0.85-1.43$ \\
\hline & 1953 & & & 0.66 & $0.48-0.92$ & & & 1.15 & $0.87-1.52$ \\
\hline & 1954 & & & 0.66 & $0.46-0.94$ & & & 1.14 & $0.85-1.53$ \\
\hline & 1955 & & & 0.63 & $0.43-0.91$ & & & 1.12 & $0.82-1.52$ \\
\hline & 1956 & & & 0.73 & $0.49-1.08$ & & & 1.06 & $0.76-1.47$ \\
\hline & 1957 & & & 0.71 & $0.47-1.09$ & & & 1.05 & $0.74-1.47$ \\
\hline & 1958 & & & 0.64 & $0.41-1.00$ & & & 1.00 & $0.70-1.44$ \\
\hline & 1959 & & & 0.52 & $0.33-0.83$ & & & 1.05 & $0.72-1.53$ \\
\hline & 1960 & & & 0.56 & $0.34-0.92$ & & & 1.05 & $0.70-1.56$ \\
\hline \multirow{2}{*}{\multicolumn{2}{|c|}{$\begin{array}{l}\mathrm{N} \\
\text { Deaths }\end{array}$}} & \multicolumn{2}{|c|}{83,578} & \multicolumn{2}{|c|}{83,578} & \multirow{2}{*}{\multicolumn{2}{|c|}{$\begin{array}{c}126,747 \\
38,455\end{array}$}} & \multicolumn{2}{|c|}{126,747} \\
\hline & & \multicolumn{2}{|c|}{28,938} & \multicolumn{2}{|c|}{28,938} & & & & 8,455 \\
\hline
\end{tabular}




\section{Supplementary Information}
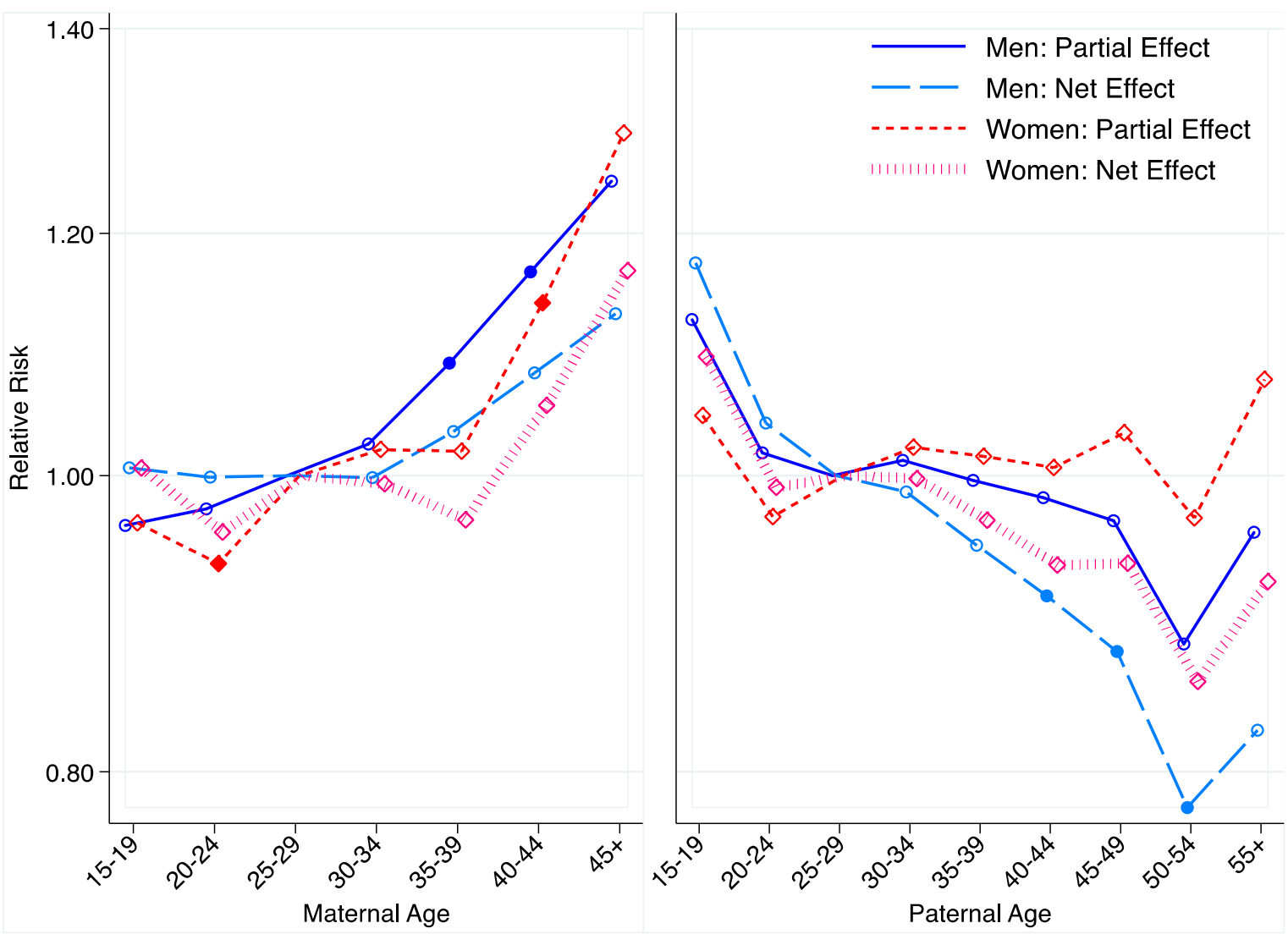

FIGURE S1. Maternal and Paternal Age at the Time of Birth and All-cause Mortality for Swedish Men and Women Born 1938-1960. Error Bars are 95\% Confidence Intervals. Note: Hollow Data Points Indicate Lack of Statistical Significance, While Filled Data Points Indicate That the Point Estimate is Statistically Significant. 

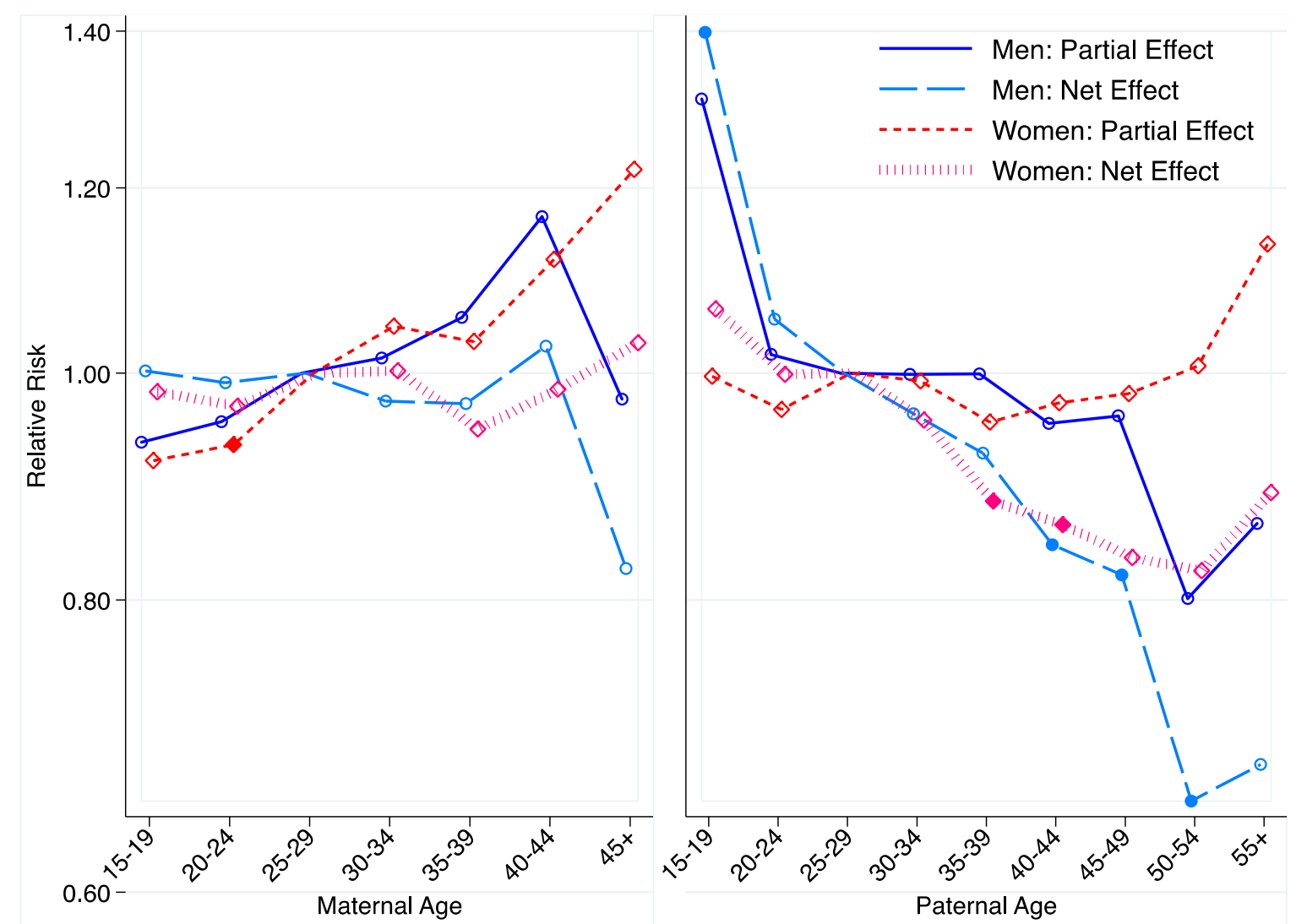

FIGURE S2. Maternal and Paternal Age at the Time of Birth and Mortality Attributable to Neoplasms for Swedish Men and Women Born 1938-1960. Error Bars are 95\% Confidence Intervals. Note: Hollow Data Points Indicate Lack of Statistical Significance, While Filled Data Points Indicate That the Point Estimate is Statistically Significant. 

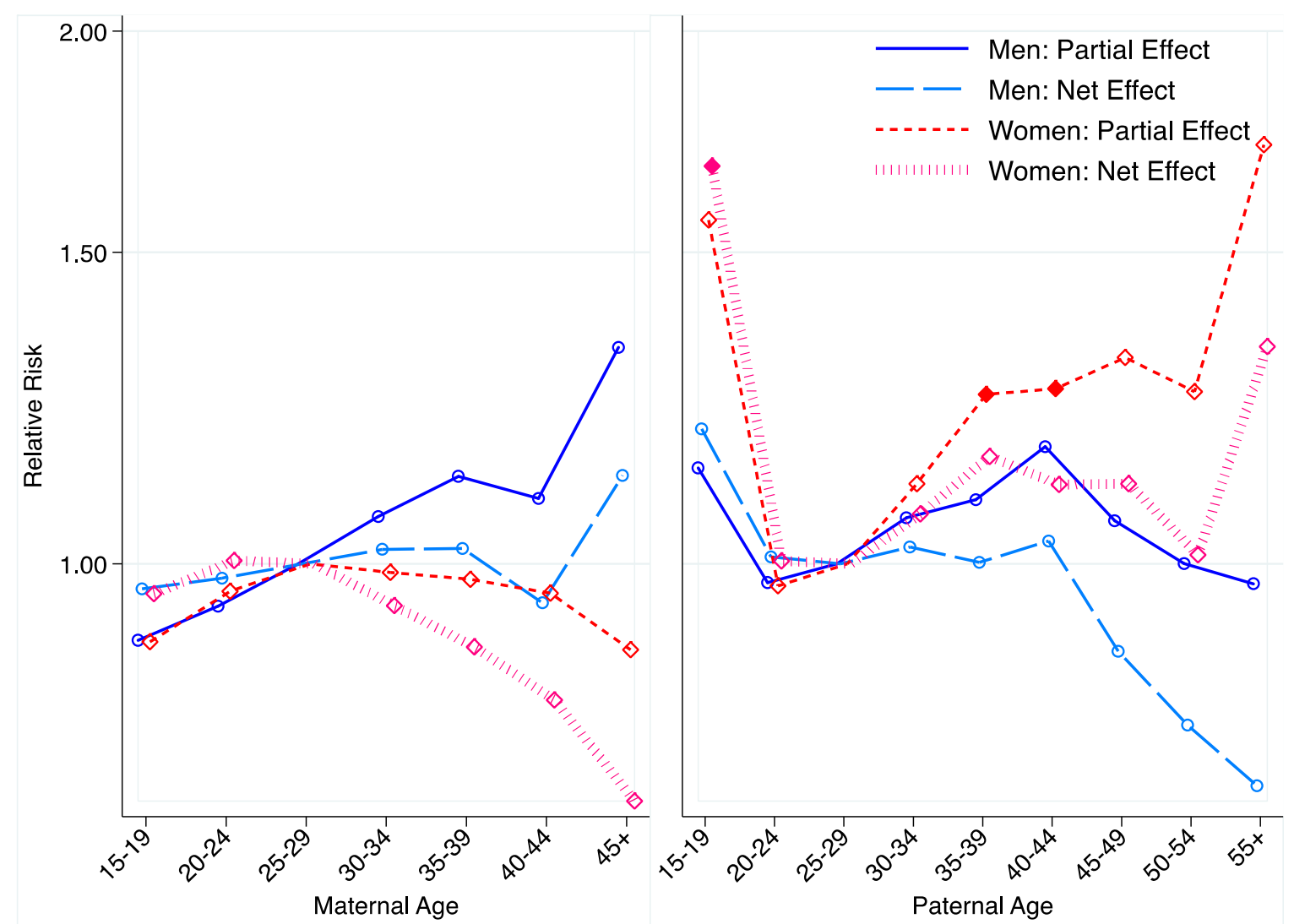

FIGURE S3. Maternal and Paternal Age at the Time of Birth and Mortality Attributable to Cardiovascular Diseases for Swedish Men and Women Born 1938-1960. Error Bars are 95\% Confidence Intervals. Note: Hollow Data Points Indicate Lack of Statistical Significance, While Filled Data Points Indicate That the Point Estimate is Statistically Significant. 

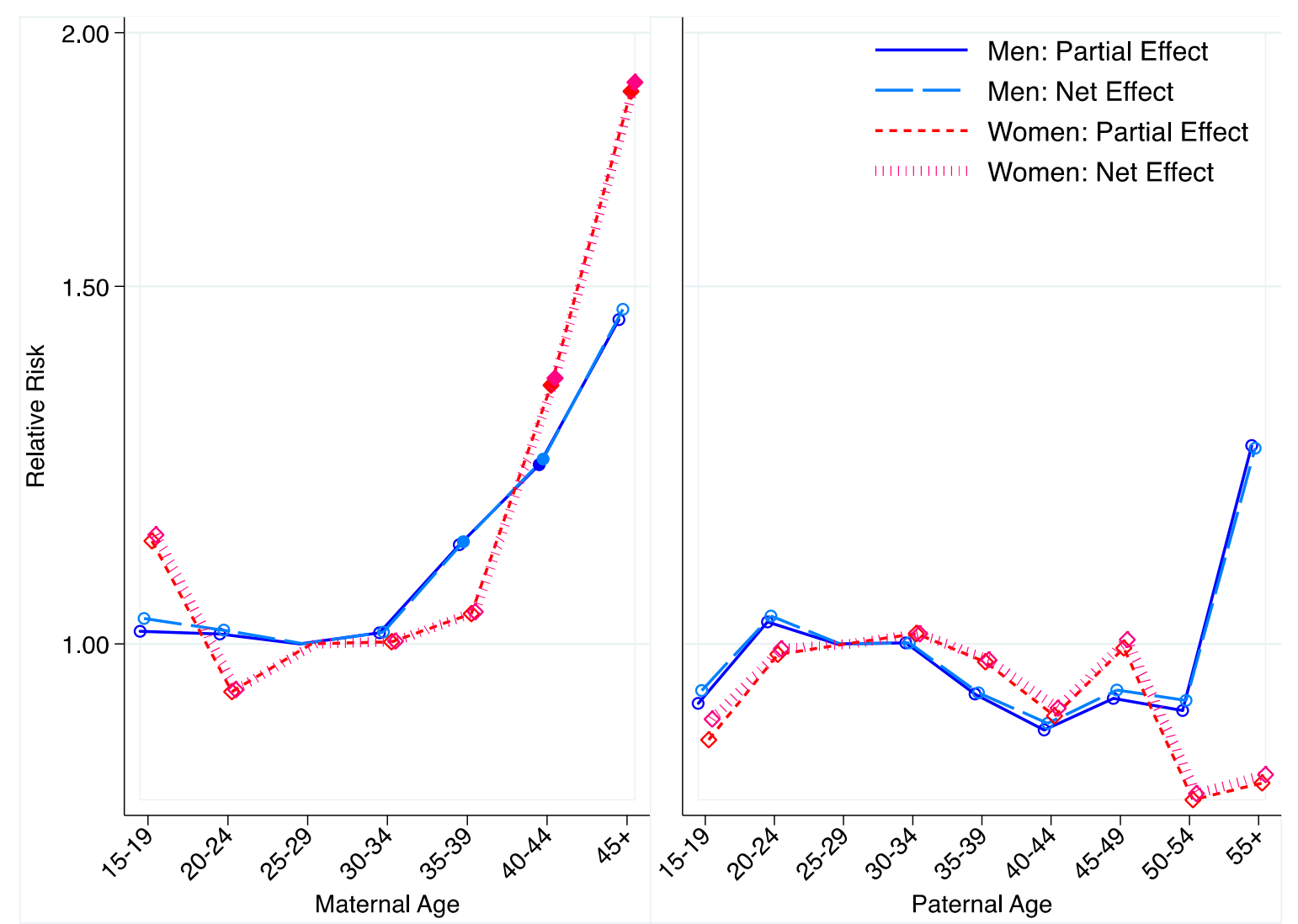

FIGURE S3. Maternal and Paternal Age at the Time of Birth and Mortality Attributable to All Other Causes for Swedish Men and Women Born 1938-1960. Error Bars are 95\% Confidence Intervals. Note: Hollow Data Points Indicate Lack of Statistical Significance, While Filled Data Points Indicate That the Point Estimate is Statistically Significant. 